\title{
Does Hydration Status Have An Effect on Wrestling Performance in High School Wrestlers?
}

Joseph M. Brausch

West Virginia University

Follow this and additional works at: https://researchrepository.wvu.edu/etd

\section{Recommended Citation}

Brausch, Joseph M., "Does Hydration Status Have An Effect on Wrestling Performance in High School Wrestlers?" (2011). Graduate Theses, Dissertations, and Problem Reports. 4699.

https://researchrepository.wvu.edu/etd/4699

This Thesis is protected by copyright and/or related rights. It has been brought to you by the The Research Repository @ WVU with permission from the rights-holder(s). You are free to use this Thesis in any way that is permitted by the copyright and related rights legislation that applies to your use. For other uses you must obtain permission from the rights-holder(s) directly, unless additional rights are indicated by a Creative Commons license in the record and/ or on the work itself. This Thesis has been accepted for inclusion in WVU Graduate Theses, Dissertations, and Problem Reports collection by an authorized administrator of The Research Repository @ WVU. For more information, please contact researchrepository@mail.wvu.edu. 
Does Hydration Status Have An Effect on Wrestling Performance in High School Wrestlers?

Joseph M. Brausch

Thesis Submitted to the College of Physical Activity and Sport Sciences

at West Virginia University in partial fulfillment of the requirements for the degree of

Master of Science in Athletic Training

Michelle Sandrey, Ph.D., ATC, Chair

Randy Bryner Ph.D

Shelly Pruett, Ph.D., ATC

Department of Athletic Training

Morgantown, West Virginia

2011

Keywords: Hydration, Performance, Wrestling 


\section{ABSTRACT}

Does hydration status have an effect on wrestling performance in high school wrestlers?

\section{By Joseph M. Brausch}

Context: Hydration is important for all athletes not only for overall health, but for optimal performance during competition. Many studies have shown a relationship between a decrease in physiological function and performance as related to dehydration typically by measuring peak power output and aerobic capacity. But few studies have shown the relationship between hydration or dehydration and the performance of wrestlers throughout a competitive season. Objective: The purposes of this study were to determine: 1) if there is a difference between hydration levels over three time points between a high specific gravity group and a low specific gravity group; 2 ) if those who have the lower average specific gravity have a higher win percentage and; 3 ) if those who have a lower average specific gravity earn more team points throughout a competitive season. Design: This study was a longitudinal prospective comparative study. The independent variables for the first design were the three time points measured; baseline, 24-hours pre-competition (24PC), and pre-competition (PC), and a high average specific gravity group (HSG, >1.02) and a low average specific gravity group (LSG, $\leq 1.02$ ). The dependent variable was the specific gravity. The second design independent variable was based on two groups: HSG and LSG. The dependent variable was win percentage. The independent variable for the third purpose was based on two groups as well: HSG and LSG. The dependent variable was team points earned by the wrestler. Setting: The study took place at a Division AAA high school in Western Pennsylvania. Patients or Other Participants: Voluntary high school wrestlers between the ages of 14 and 18 (16.53 \pm 1.41 yrs) and grades 9-12 were used for the study. Subjects were excluded from the study if they did not participate in at least $75 \%$ of matches throughout the competitive season. Interventions: Specific gravity of urine and body weight was measured at baseline, 24 hours before a competition and then again the day of the competition, 2-3 hours before the start of the first match for home matches. For away competitions specific gravity was measured before the bus left for the match. Win percentages were calculated from dual meets as well as the first day of tournaments. Team points based on performance were measured on the outcome of each individuals match during dual meets as well as the first day of tournaments. Main Outcome Measures: The investigator believed that specific gravity would change over time with the LSG showing less variability than HSG. Those athletes in the LSG (i.e. more hydrated) will show a higher win percentage and earn more team points during those matches. Results: There was a significant time by group interaction $(\mathrm{P}=.005)$, for the HSG at baseline $(\mathrm{P}=.045)$ and HSG at 24PC $(\mathrm{P}=.004)$. A main effect for time $(\mathrm{P}<.001)$ for all 3 time points: baseline to $24 \mathrm{PC}(\mathrm{P}<.001)$, baseline to $\mathrm{PC}(\mathrm{P}<.001)$, and 24PC to $\mathrm{PC}(\mathrm{P}=.041)$. LSG had an average team point total of $14.33 \pm 7.74$. HSG had an average team point total of $32 \pm 14.34$. There was a significant difference between the two groups $(\mathrm{P}=.024)$ with HSG earning more team points. All other results showed no significance. Conclusions: The results of this study show a group by time interaction at baseline and 24PC with HSG being lower at baseline but higher at 24PC. A main effect for time showed specific gravity does change significantly from baseline to $24 \mathrm{PC}$, baseline to $\mathrm{PC}$, and $24 \mathrm{PC}$ to $\mathrm{PC}$, and is significantly higher 24PC and PC than baseline. Also there was a significant difference between the groups for team 
points. However, HSG scored significantly more team points than LSG. There was no significant difference measured between groups when compared to win percentages. 


\section{ACKNOWLEDGEMENTS}

I would like to thank my family for their support and patience with me. Without my mom and dad I would not have had the drive to get to where I am today.

I would like to thank the Albert Gallatin Administration and Coaching staff, specifically Duane Dupont, the Athletic Director for allowing me to utilize their facilities and the Albert Gallatin wrestling team for having the patience to take so many tests during the course of the study.

I would like to thank Dr. Michelle Sandrey for all of her help and guidance in completing this study. Without her this study would never have been finished.

I would like to thank Dr. Shelly Pruett for always having her door open when I needed to talk about any issues and her guidance.

I would like to thank Dr. Randy Bryner for always being open to questions and explaining the physiology of the human body in terms that I could always understand. 


\section{TABLE OF CONTENTS}

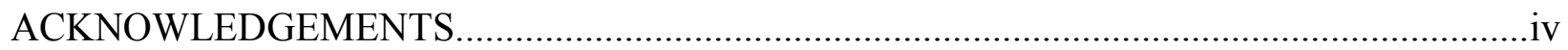

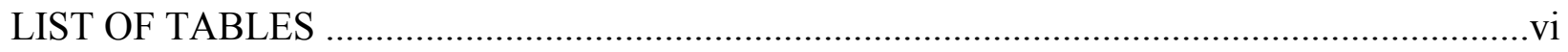

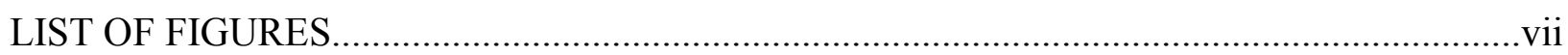

INTRODUCTION

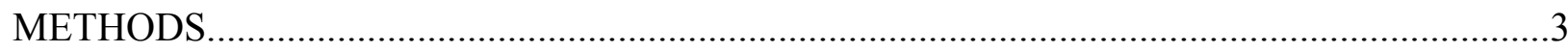

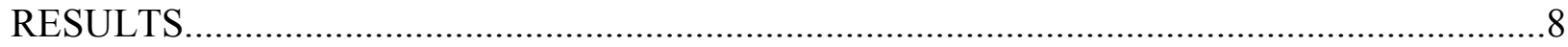

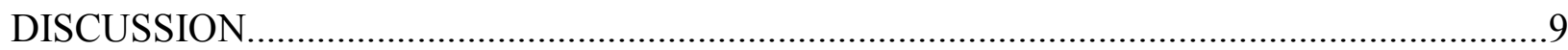

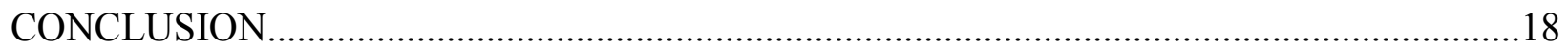

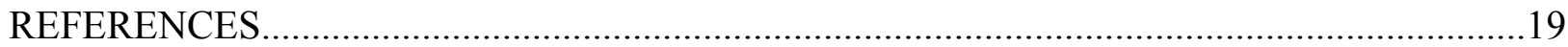

APPENDICES

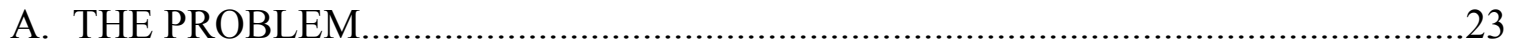

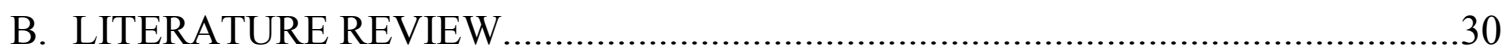

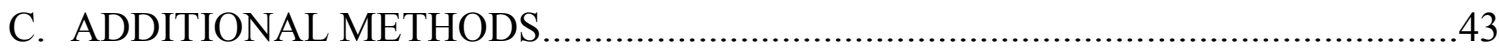

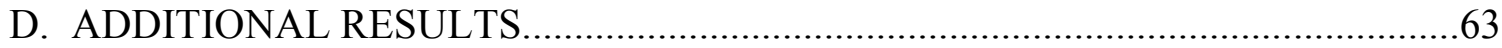

E. RECOMMENDATIONS FOR FUTURE RESEARCH.......................................67

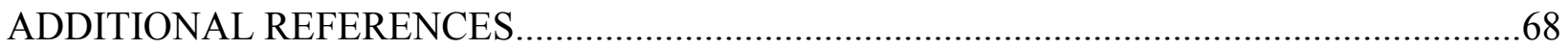


Table

LIST OF TABLES

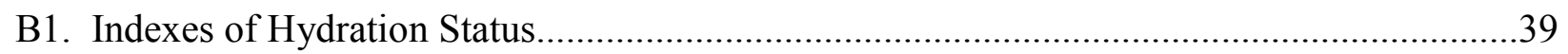

C1. Parent/Guardian Informed Consent/ Information......................................................43

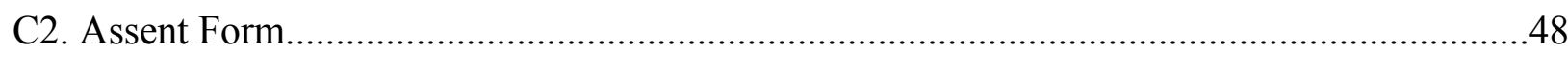

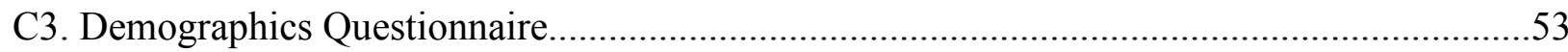

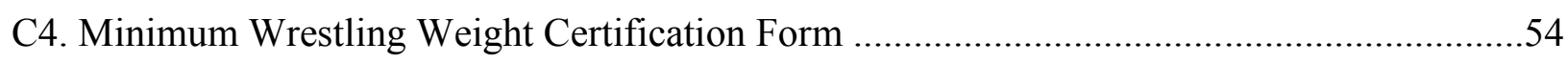

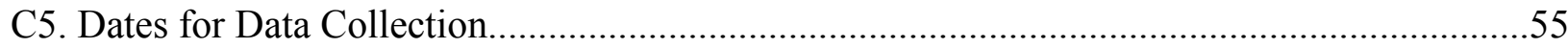

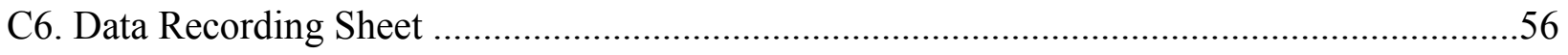

C7. Testing Procedures for Specific Gravity and Weight.......................................................57

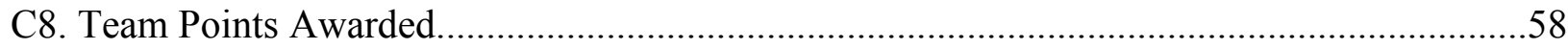

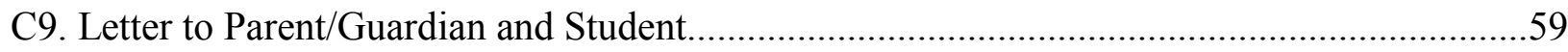

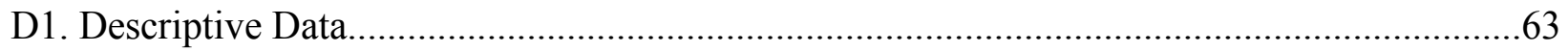

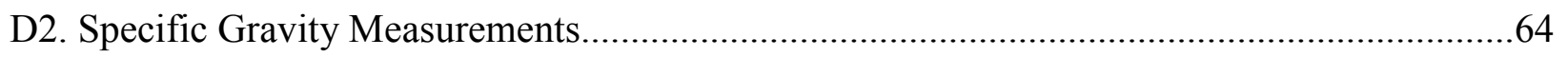

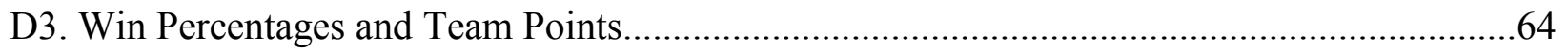




\section{LIST OF FIGURES}

Table Page

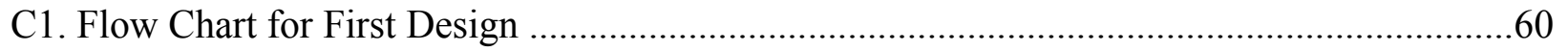

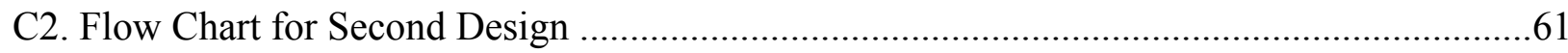

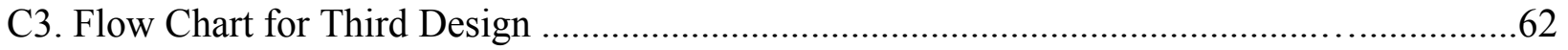

D1. Specific Gravity Measurements Over Time......................................................................65

D2. Specific Gravity Measurement for Group and Time ................................................65

D3. Average Specific Gravity and Percentage Weight Change.............................................66 


\section{INTRODUCTION}

Every athlete in every sport would like to gain a competitive advantage over their opponents. In wrestling many coaches and athletes believe that the answer is to drop weight to compete in a lower weight class. This will cause a perceived gain in speed, size, and perhaps a strength advantage over an opponent that may allow the wrestler to outperform and beat the competition. ${ }^{1,2,3}$ Although controversial, many attempt to reach a lower weight class by rapidly dropping weight through dangerous practices such as intentional dehydration. ${ }^{4}$ Dehydrating oneself is perceived to be the quickest and easiest way to drop excessive weight. It is often performed by increasing exercise intensity and frequency as well as decreasing or even ceasing food and water consumption. ${ }^{1,5}$ All too often high school and college wrestlers attempt to drop too much weight which can impair performances and in some drastic cases even cause death. In 1997 three college wrestlers died after attempting to drop up to $15 \%$ of their body weight in one week. This was done by fasting, dehydration, and increasing exercise ${ }^{6,7}$ Following these disasters, the NCAA began to develop hydration testing procedures that would limit the amount of weight athletes could drop each week as well as overall throughout the season. The NWCA and NFSHSA soon followed and the hydration test is now required for high school athletes.

Water constitutes a large percentage of the human body, between $50-65 \%$ for females and between $55-70 \%{ }^{8,9}$ Water is essential for proper function of the body down to the cellular level. A small decrease in normal hydration status, as low as $2-3 \%$ results in numerous physiological and psychological problems. These range from decreased cardiovascular status, ${ }^{8}$ decreased ability for heat dissipation, ${ }^{8}$ a decrease in cardiac stroke volume, ${ }^{10,11,12}$ increased resting heart rate, ${ }^{10,13}$ decreased muscular strength and power, ${ }^{10}$ increased stress response, an increased perception of effort, decreased ability to regulate pace, to a decrease in work completed. ${ }^{13}$ These 
responses can have a large effect on physiological performance and therefore damage competitive performance and outcome. Almost all, $80-90 \%$ of wrestlers, ${ }^{12,}{ }^{14}$ admit to practicing some form of weight loss technique in order to reach a lower weight class. The most common are dieting and increasing exercise intensity or frequency. ${ }^{5}$

It is because these athletes often use dangerous weight loss practices and in many cases do not control weight gain after competitions that hydration testing is now required. Each season before competition begins wrestlers are required to pass a hydration test. During a hydration test urine specific gravity is analyzed with a refractometer. If specific gravity is below 1.025 the wrestler is considered euhydrated and can proceed with the test, if not the test is failed and there is a 24 hour waiting period before the test is attempted again. After passing the hydration part of the test, a three site skin-fold body fat analysis is performed and then weight is taken. These numbers are entered into an online computer program to determine a minimum wrestling weight and the amount of weight a wrestler can lose, ensuring to not exceed $1.5 \%$ of body weight per week. ${ }^{15}$

Despite the importance of hydration there has been very little research analyzing wrestling performance during a competitive match under different hydration levels. More often researchers evaluate muscular strength ${ }^{16}$ and/or peak power output ${ }^{17}$ because of the objective qualities of the results. These studies have not considered competition performance because it is difficult to measure. During a competitive wrestling match numerous variables can influence outcomes. There is no completely objective measure to classify performance during competition; however one can use team points earned from the outcome of a match to determine how well the individual performed. In addition, very little research has been conducted on the effect of hydration on competitive performance throughout the wrestling season. Therefore the 
objectives of this study were to determine if: 1) there is a difference between hydration levels over three time points between a high specific gravity group and a low specific gravity group; 2 ) those who have a lower average specific gravity have a higher win percentage and; 3) those who have a lower average specific gravity earn more team points throughout a wrestling season.

\section{METHODS}

This study was a longitudinal prospective comparative design that analyzed data at 12 time points throughout the regular wrestling season (December 9, 2010- February 5, 2011). The first design independent variables were the three time points measured: baseline, 24-hours precompetition (24PC), and pre-competition (PC), the two groups: a high average specific gravity group (HSG, >1.02) and a low average specific gravity group (LSG, $\leq 1.02)$. The dependent variable was the specific gravity throughout the season. The second design independent variable was the HSG and the LSG groups as determined by the average specific urine gravity. The dependent variable was the win percentages between each group. The third design independent variable was the HSG and the LSG groups. The dependent variable was the average team points earned by the group throughout the season.

Subjects

Using a sample of convenience, wrestlers at one high school in Western Pennsylvania volunteered to participate. Fifteen high school wrestlers from grades 9-12, ages 14-18 (16.53 $\pm 1.41 \mathrm{yrs})$, weight classes 103-285, and various skill levels started the study. Twelve subjects were included in the study and completed the study in entirety. Because of this all but three weight classes $(103,112,189)$ were represented. In order to remain eligible for the study, subjects had to wrestle in at least $75 \%$ of competitions. Subjects that became injured or ill 
during the season could not miss more than 3 competitions or they were excluded from data analysis. This study was approved by the Institutions Office of Research Compliance. Instruments

Specific gravity of urine was measured with a portable Refractometer REF\# 312 ATC Protein, Urine (General Tools, New York, NY), and was calibrated daily by the researcher using distilled water before any measurements were taken. A refractometer has a validity of $.97^{18}$ reliability of .998. ${ }^{19}$ Skin fold tests were measured by a Lange Skin Fold Caliper (Beta Technology Inc., Cambridge, MD). The Lange Skin Fold Caliper is accurate to $\pm 1 \mathrm{~mm}$ and is calibrated using a calibration block. All weight measurements were taken using a digital scale accurate to $0.1 \mathrm{lbs}$ (Befour Inc. Saukville, WI) which is calibrated yearly by Fayette County, PA Chief Sealer (November 2010).

Testing Procedures

Athletes and parents were informed of the study and the purpose at a meeting before the season began. Informed Consent forms (Table C1) and Assent forms (Table C2) with HIPPA information for the parents and subjects were given to each prospective subject as well as an information sheet describing the purpose of the study. Subjects were given a confidential and coded demographic questionnaire (Table C3) which was used for descriptive analysis. Subjects reported on the scheduled date for the mandated state certification test (Table C4), which could not be earlier than October $29^{\text {th }}, 2010$. Data was collected before the beginning of the season for the mandated state certification. All subjects were given the mandated test at least two weeks prior to the first competition. The mandated test required a urine sample for specific gravity, a three site (triceps, subscapular, and abdominal) skin fold body fat analysis, and overall body weight. All subjects were identified by a code during weigh-ins and for sample collection to 
ensure privacy. Throughout the season, specific gravity and weight were collected 24 hours prior to competition, as well as the day of competition. For home competitions hydration testing were performed 24 hours before the match and again 2 hours before competition began. For away competitions hydration testing was performed 24 hours before the match and again before the athletes left on the bus for the competition. A total of 16 samples per wrestler were collected throughout the season and measured for specific gravity. Data obtained from the mandated test was used as a baseline for all subjects and used to compare to later results. Data was collected on 16 separate dates (Table C5). All information was recorded on a data sheet (Table C6). Refractometer Testing Procedures

A refractometer was used to measure specific gravity of urine. The refractometer was calibrated daily by the recorder. This was done by placing a drop of distilled water onto the glass plate. A small screw on top of the instrument was used to calibrate the specific gravity of the distilled water at 1.000 (Table C7). The researcher wore latex gloves to prevent any risk to the researcher while handling bodily fluids and changed gloves between each subject. All subjects were asked to provide a small urine sample into a plastic cup in a private bathroom. A drop of urine was placed on the glass plate of the refractometer using a pipette and the specific urine gravity was read through the periscope by the researcher. The remaining urine in the sample cup was disposed of by the individual in the lavatory. The sample cup was then placed into a biohazard container. The specific urine gravity was recorded on the data sheet. The refractometer was then cleaned by using distilled water to wash the urine off of the glass plate into a biohazard container as directed by the manufacturer instructions. The glass plate did not have any residual liquid. A soft rag was used to dry the glass plate which was then disposed of in the biohazard container as well. The pipette that was used to obtain the drop of urine was also 
placed into the biohazard container. The biohazard container was disposed of following School Board procedures.

Weight Testing Procedures

The subjects were then asked to stand on the center of the digital scale barefoot but in whatever clothes they wish, which usually consisted of undergarments. Wrestlers were asked to stand as still as possible while the weight was read and recorded. Wrestler's weight was recorded on the data sheet to within a tenth of a pound.

Data Analysis

For objective one, subject data was entered into a spreadsheet depicting all 24 data collection times. Each data collection period of 24 hours pre-competition and again precompetition was taken throughout the competitive wrestling season excluding post-season competitions. Due to delay for IRB approval, cancellation and scheduling issues due to weather, and a match being canceled due to a team discontinuing the program, 4 matches were excluded. Next, subject's average specific gravity was calculated by:

(specific gravity value for 24 hour pre-competition $1+2+3+\ldots 8) / 8$ and

(Specific gravity value for pre-competition $1+2+3+\ldots 8) / 8$.

For objective two, the average specific gravity was calculated throughout the season for each subject by combining the 824 -hour pre-competition and 8 pre-competition measurements. Subjects were placed into a high specific gravity group ( $>1.02 \mathrm{sg})$ or a low specific gravity group $(\leq 1.02 \mathrm{sg})$, grouping was decided by those with an average specific gravity above or below 1.02 which is considered the upper limit for mild dehydration. ${ }^{20}$ The average of these measurements was taken by: 
(Specific gravity measurement $1+2+3+4+\ldots 16) /($ total \# of competitions wrestled $x 2)$. Win percentage was calculated by:

(Total \# of wins/ Total \# of matches) x 100.

For objective three, each individual's team points were calculated based on points earned during match performances. Subjects were placed in HSG and LSG based on average specific gravities throughout the season then team points were averaged for both the HSG and the LSG groups. Forfeits were eliminated as an individual would earn 6 team points however no match was actually wrestled. Team points were awarded based on how a wrestler performed during a match. For example a pin in the first period was awarded 8 team points to signify a better performance than a pin the second period (Table C8). Each group had team points averaged for the entire group by:

( subject 1 total team points + subject 2 total team points...+ subject 6 total team points)/ total number of subjects in the group.

Statistical Analysis

A 2-way Repeated Measures Analysis of Variance (ANOVA) was used in place of an Analysis of Covariance (ANCOVA) to determine if there was a difference between a high specific gravity group (HSG, >1.02) and a low specific gravity group (LSG, <1.02) over time at baseline, 24-hours pre-competition and day of-competition. A one-way Repeated Measures Analysis of Variance (ANOVA) test was used to assess if there was a difference between the HSG and LSG groups and win percentages. Another one-way Repeated Measures ANOVA was used to analyze the average levels of specific gravity between the HSG and LSG groups to total team points earned. Statistical significance was measured for all analyses using $\mathrm{P}=0.05$. All 
statistical tests were performed using SPSS for Windows computer software (Version IBM 19.0, SPSS. Inc., Chicago, IL).

\section{RESULTS}

Demographic Information

Refer to table D1 for descriptive statistics. There were 15 subjects who started the study. Three subjects were excluded because they did not meet eligibility criteria. All three did not compete in $75 \%$ of competitions required by the study. Therefore, only data for 12 subjects was used in data analysis. Approximately $46.7 \%(\mathrm{n}=7)$ of subjects were seniors. Thirteen and one third percent $(n=2)$ of subjects were juniors, $6.6 \%(n=1)$ of subjects were sophomores, and $33.3 \%(n=5)$ of subjects were freshmen. All but three weight classes $(103,112,189)$ were represented by subjects. All subjects reported wrestling for a minimum of 2 yrs and a maximum of 10 years. The mean number of years wrestled was $5.2 \pm 2.43$ yrs with the majority $(73.3 \%$, $\mathrm{n}=11)$ wrestling for 6 years or less. The majority of subjects $(93.3 \%, \mathrm{n}=14)$ reported attempting to lose weight weekly with an average of $5.07 \pm 2.49$ lbs per week.

Changing Hydration Levels Over Time

Refer to Table D2 for descriptive statistics. All 12 subjects who completed the study and were eligible had baseline specific gravity measured which was compared to the average specific gravities 24-hours prior to competition and average specific gravity the day of competition. There was a significant interaction between time and group $\left(\mathrm{F}_{1,2}=12.926, \mathrm{P}=.005\right)$. The difference between groups at baseline was significant $(\mathrm{P}=.045)$ with the HSG having a lower specific gravity than the LSG. There was also a significant difference at 24-hours precompetition $(\mathrm{P}=.004)$ with the HSG having a higher average specific gravity. There was not a significant difference for any group the day of competition $(\mathrm{P}=.073)$. There was a significant 
main effect for time $\left(\mathrm{F}_{1,2}=8.84, \mathrm{P}=.016\right)$. A significant change between each time point was noted for baseline to 24-hours pre-competition $(\mathrm{P}<.001)$, baseline to pre-competition $(\mathrm{P}<.001)$ and from 24-hours pre-competition to day of competition $(\mathrm{P}=.041)$. There was no significant main effect for groups $\left(\mathrm{F}_{1,2}=.169, \mathrm{P}=.69\right)$.

A line graph was developed to compare average specific gravity and average percent of weight change for the eight matches. As noted from the graph, as specific gravity decreased, percentage weight change also decreased. This ranged from $0.9 \%$ at the fifth match to $2.2 \%$ at the first match. (Figure D3) Specific Gravity Affecting Win Percentages and Team Points

Refer to Table D3 for descriptive statistics. Subjects were grouped into LSG $(<1.02)$ and HSG (>1.02) for win percentage and team points. There was not a significant difference between the group's average specific gravity and win percentages ( $\left.\mathrm{F}=4.093_{1}, \mathrm{P}=.071\right)$. There was a significant difference $\left(\mathrm{F}_{1,2}=7.054, \mathrm{P}=.024\right)$ between the two groups as the HSG scored more team points. Low specific gravity group had an average team point total throughout the season that was lower than HSG.

\section{DISCUSSION}

The purpose of this study was to determine if: 1) there is a difference between hydration levels over three time points between two groups at baseline, 24-hours pre-competition and precompetition, 2) those who have the lowest average specific gravity have a higher win percentage, and 3) those who have a lower average specific gravity earn more team points throughout a season. Overall there was a significant interaction between groups over time at baseline, 24 hours pre-competition, but not at pre-competition. Subjects in HSG had a lower baseline specific gravity than those in LSG; however, for the 24-hour pre-competition results HSG had a higher 
specific gravity. There was also a significant change in specific gravities between each time point at baseline to 24 hours pre-competition, baseline to pre-competition and 24 hour precompetition to pre-competition. There was a significant difference between the HSG and LSG with team points; with the HSG earning more team points during the season. Win percentages was not affected by being in either the high or low specific gravity group.

\section{Changing Hydration Levels Over Time}

The first hypothesis of this study stated there was a difference between the two groups at baseline, 24 hours pre-competition, and pre-competition, more specifically that the wrestlers in the low specific gravity group would have a lower specific gravity at all three time points. At baseline the HSG had a lower average specific gravity than the LSG. However at 24 hours precompetition the HSG had a higher average specific gravity than the LSG. At pre-competition, although the HSG group was on average higher, there was no difference as average specific gravity also increased in the LSG group. Due to little variability in the means neither group was different. Therefore this hypothesis was rejected.

Subjects had a higher specific gravity the day of competition than the day before competition, and both time points were higher from baseline indicating that the subjects were in a more dehydrated state for competitions than any other time of data collection. In this study wrestlers in both groups were at the level of significant dehydration ${ }^{20}(1.030)$ at $24 \mathrm{PC}$. At PC the LSG group was at significant dehydration while the HSG ranged from significant to serious dehydration (>1.030). ${ }^{20}$ At different time points some subjects were beyond $3 \%$ dehydrated between 24PC and PC. For one to have a detrimental effect on cardiovascular status, heat dissipation and athletic performance, only a 2-3\% level of dehydration is needed. Many wrestlers do not adhere to the guidelines set in place by the NWCA and will spend the last two to three 
days before each competition attempting to drop weight gained between the previous competition and the upcoming one through dangerous and rapid weight loss techniques such as intentional dehydration. Young adults that restricted fluids even without restricting food resulted in a deficiency of $2.7 \mathrm{~L}$ of body water over a 37 hour time period. After 24 hours there was a loss of body weight of $1.8 \%$ and after 37 hours a body weight loss of $2.7 \% .{ }^{21}$ All but one subject reported losing weight weekly in order to make weight for a competition and there was usually a decrease in weight from 24-hours pre-competition to pre-competition measurements. A wrestlers weight loss practices can dramatically affect how the subject would perform. It is documented that nearly $80 \%$ of wrestlers use dieting for weight loss, over $50 \%$ use fasting, and $75 \%$ increase exercise routine. ${ }^{5}$ Some wrestlers use other more dangerous methods. Nearly $34 \%$ report using rubber suits, $14 \%$ reported using saunas, and $8 \%$ reported self induced vomiting to lose weight. ${ }^{22}$ Unknown to those performing the study and the coaching staff, one subject reported after the season that he frequently used a rubber suit after practices to maintain his core temperature in an attempt to lose more weight at home. This practice is illegal in wrestling due to the dangers it can create. Two of the wrestlers that died in 1997 were using rubber suits to increase perspiration rate while attempting to lose more weight. One of those wrestlers autopsy revealed that he died from rhabdomyolysis or a cellular break down of muscles, combined with kidney failure and heart malfunction. ${ }^{23}$ This dieting and/or fasting could included large amounts of fluid restrictions, leading to dehydration.

To determine the amount of weight a wrestler can lose per week safely, preseason body weight and body fat percentage in a euhydrated state is measured and this information is placed into the optimal performance calculator on the NWCA website. This hydration testing helps to minimize the potential risks of intentional dehydration by only allowing the wrestler to compete 
in specific weight classes by certain dates and also creates a minimum weight class that the wrestler can reach. ${ }^{8}$ Athletes are given some time to recover and consume fluids between weight-ins and match time, but not enough to return to normal, euhydrated values as described in other studies. ${ }^{12}$ It may take $24-48$ hours to reestablish fluid homeostasis, and up to 72 hours to replenish muscle glycogen stores. ${ }^{4}$ When matches begin, if the wrestler is in a dehydrated or severely dehydrated state performance will be affected. If dehydration affects performance there will not be an adequate time frame enabling the wrestler to regain a euhydrated state. Oppliger et al. ${ }^{5}$ stated that to be euhydrated, bodyweight must stay within $0.45 \mathrm{~kg}(0.991 \mathrm{bs})$ day to day, a fluid intake for normal urine volume and concentration, a relatively stable level of intracellular and extracellular body water exists, and a normal blood chemistry make up. ${ }^{5}$ As average specific gravity decreased among subjects, percentage of weight change also decreased. Oppliger ${ }^{5}$ recommended body weight be maintained within 0.991 bs day to day. However, many subjects lost much more weight that what is recommended to stay within a euhydrated state. On multiple occasions subjects lost up to $4.5 \%$ of bodyweight and as much as $6.51 \mathrm{lbs}$ in 24 hours far exceeding recommended values to maintain a euhydrated state.

As will be discussed later specific gravities did not have a significant effect on win percentages, and therefore those who are more experienced or have participated in state mandated hydration testing may have better win percentages. Being familiar with this procedure, those subjects were more prepared for the test and were more hydrated during the mandated testing. There were no significant differences between groups alone, but the HSG was lower at baseline and higher at 24-hours pre-competition and pre-competition. The literature states and also confirms what organizations like the National Collegiate Athletic Association (NCAA) and the National Federation of State High School Associations (NFSHSA), and the 
National Wrestling Coaches Association (NWCA) attempt to control weight classes and weight loss with required hydration testing. Unfortunately, after baseline no other specific gravity measurements are obtained, so detrimental effects throughout a season cannot be determined. Specific Gravity Affecting Win Percentage and Team Points

The second hypothesis stated that those wrestlers who had been placed in the lower average specific gravity group would have a higher win percentage. Therefore the hypothesis was rejected. The third hypothesis stated that those wrestlers in the high average specific gravity group would earn less team points than the lower specific gravity group. Subjects in the higher specific gravity group had earned significantly more team points during the season than the low specific gravity group, and therefore the hypothesis was rejected as there was no difference between groups.

Studies ${ }^{10,13,20,26,27,28}$ have shown that physiologically, as well as stress response, perception of effort given and anticipatory regulation of pace, hypovolemia, hyperosmolality, and a decrease in overall work completed can be affected by dehydration, According to these studies, subjects in HSG should not have been able to perform at the same level as the LSG. This infers that there was another factor or factors that influenced performance. It is believed from this study that many subjects in the HSG had more experience than those in the LSG based on higher team points earned and higher win percentages. In general athletes in most sports will perform better if they have been involved in the sport for a longer period of time. An athlete who has been competing in a sport for 6 years will likely do better and have more skill than an athlete having competed for only 1 or 2 years. Anecdotal evidence suggests that factors such as experiences, psychosocial factors, muscular strength and endurance, and overall skill were the reasons for the higher win percentages and team points in the HSG. One subject in particular 
had a win percentage of $100 \%$ during those matches that were recorded and multiple subjects had win percentages of $89 \%$ in the HSG, while the highest win percentage of one subject in LSG was $67 \%$. This opens new questions such as at what point is specific gravity high enough to affect performances. It is widely accepted that dehydration plays a key role in performance, but it is unknown what an optimum level specific gravity should be at for peak performances.

Dehydration and rapid weight loss can also result in decreased muscle glycogen, plasma volume, and buffering capacity of blood which could impact a subject's performance. ${ }^{26}$ In a study performed by Roemmich and Sinning ${ }^{29}$ weight loss was compared to wrestler's growth, maturation, body composition, protein nutrition, and muscular strength at the end of a wrestling season and again 3.5-4 months later. Weight loss was controlled only by diet. A control group was given adequate amounts of calories, carbohydrates, proteins, and fats. This group had normal weight gains. The second group of wrestlers was given a high-carbohydrate and low fat diet. These subjects did not receive enough energy or protein in the time frame. These subjects showed a decrease in protein nutrition and muscular performance. In contrast to what many wrestlers believe that cutting weight to reach a lower weight class will give them an edge over an opponent, wrestlers with a deficient diet had reduced strength in arms and legs. ${ }^{29}$ In order for an athlete to reach full potential it is recommended that they eat a well balanced diet of carbohydrates, fats, and proteins. When an athlete's diet is compromised there can be a decrease in muscle glycogen levels as well and studies ${ }^{11,27}$ have confirmed that decreased glycogen levels can reduce performances. During a few wrestling matches a subject reported feeling tired or sluggish, and it was noticed by the researcher that the specific gravity taken that day was higher than usual. Two subjects reported cramping during the match and afterwards, they also reported during these times feeling "worn out". Each of these times the subjects won the particular 
match, but appeared to the researcher to be fatigued and performing in a less than optimal condition during the match compared to other matches. Diet was not evaluated in this study, but should be an important consideration.

It appears that a hydrated state does not necessarily guarantee having a higher win percentage or earning more team points. Factors beyond the scope of this study should be considered. Other studies ${ }^{24,25}$ have evaluated how psychological factors relate to performance. Both Gould ${ }^{24}$ and Scanlan ${ }^{25}$ discovered that wrestlers with a higher pre-competition expectation score enjoyed the sport more, with positive parental reinforcement performed better during matches. It is unknown what the psychological state the subjects were in during the study but some may have not enjoyed the sport but simply just wanted to finish the season. One subject in particular completed many of the specific gravity testing's, but only competed in one match. He simply did not desire to compete. It is unknown what his psychological reasoning for this was as different subjects have different reasons for participating in the study. While some subjects won particular matches, it was subjectively noted that they did not appear to be performing at peak levels confirming other studies ${ }^{10,20,26,27,28}$ results that dehydration can affect performance through various means. These studies ${ }^{10,20,26,27,28,}$ have shown that dehydration affects muscular strength, cardiovascular and muscular endurance, and mental status; all factors that could contribute to a decrease in performance.

The opponents that the subjects wrestled against were not taken into account during the season. This study attempted to track opponents win percentages online as a basis of comparison but data was incomplete. In a high school setting athletes can have vastly different experience levels, skill levels, and desires for the sport. During dual meets there was no ranking system in place so the outcome could not have been anticipated and seeding changed for each tournament 
and not all opponents were represented each time so accurate rankings could not be gathered. This is important because the skill and performance of an opponent may account for why some subjects had very high or low win percentages and earned more or less team points throughout the season. It was not in the scope of this study to account for these differences, although future studies should possibly take one or more of these into account.

Clinical Implications

In general wrestlers are more dehydrated the day of a competition than the day before a competition and especially from when the state mandated test is taken. It is important to maintain a proper hydration status in all athletes for prevention of heat related illnesses and injuries that could be related to dehydration. In this study, wrestlers may still be using intentional dehydration practices in order to cut weight. Although the NWCA guidelines are helping to limit the amount of weight a wrestler can drop each week, many athletes do not follow the guidelines strictly. Some may still attempt to lose large amounts of weight quickly possibly through what may be considered dangerous practices. It is important to enlighten wrestlers about staying hydrated throughout the season and not only for the state mandated testing.

Mandated hydration testing is only performed in high school and college settings. Many athletes begin wrestling as young as five years old. By the time they reach high school, many habits have been formed, including certain weight loss practices which may be dangerous or detrimental to health and performances. It is vital for athletic trainers to talk to high school wrestlers, and even younger wrestlers, about how important safe weight loss practices are and how dehydration can affect the body. Encourage athletes who are attempting to lose weight to follow the NWCA guidelines, stay hydrated, and to eat a balanced and nutritional diet. Athletic trainers should question athletes about their weight loss practices to find out what they are doing 
and if it is dangerous, to help modify weight loss strategies. If necessary, athletic trainers need to stop those who are utilizing extreme measures such as rubber suits or pharmacological aids such as diuretics. Athletes who "crash" diet in an attempt to lose weight quickly can have unforeseen problems, but those who attempt to lose weight safely will be at a decreased risk for injury, illness, and in extreme cases even death. It may be beneficial for wrestlers to periodically perform a hydration test throughout the season to measure hydration levels. This would give insight to the athlete about how hydrated or dehydrated they are and encourage them to drink more water and compete in a hydrated state throughout the wrestling season.

\section{Limitations}

During the course of the study three subjects were not included because they did not meet inclusion criteria. Also throughout the study only 8 of 12 matches were used. Four matches were excluded for multiple reasons. One match was excluded because the study was not approved prior to the first match. Two matches were excluded because of scheduling issues where a sample was not taken 24-hours pre-competition or there were two matches scheduled in two days. One match was not included due to a team canceling the wrestling program and ending their season. Therefore, these results were not included in data analysis. Further, these

results cannot be generalized because the study used 12 subjects from one high school in western Pennsylvania. To generalize the study, subjects should be included from other high schools around the area or throughout the country.

There are other limitations and explanations as to why the hypotheses in this study were not accepted, other factors should be considered but these were not evaluated. The wrestler's weight loss practices, diet, psychological factors, skill, and each opponent wrestled may be determining factors and should be considered in subsequent studies. 


\section{CONCLUSIONS}

This study found a statistically significant relationship between the subject's hydration levels over time. Subjects had an average specific gravity much lower at baseline than at 24hours pre-competition and also pre-competition, indicating that subjects are typically in a higher dehydrated state prior to competition than even the day before competition. The subjects in the HSG group had a lower baseline specific gravity and a higher specific gravity the day before competition. Neither group was different the day of competition. Win percentages were not affected by being in a low or high specific gravity group. Team points earned was affected by being in a low or high specific gravity group. The higher specific gravity group earned more team points compared to the low specific gravity group. 


\section{REFERENCES}

1. Shriver L, Betts N, Payton M. Changes in Body Weight, Body Composition, and Eating Attitudes in High School Wrestlers. Int J Sport Nutr Ex Metab. 2009;19(4):424-432.

2. Horswill, C.A. Weight loss and weight cycling in amateur wrestlers: Implications for performance and resting metabolic rate. Int J Sport Nutr, 1993. 3(3), 245-260

3. Kiningham, R.B., , D.W. Weight loss methods of high school wrestlers. Med Sci Sports Exerc. 2001: 33(5), 810-813

4. American College of sports Medicine. ACSM position stand: weight loss in wrestlers. Med Sci Sport Exerc. 1996;28 135-138

5. Oppliger R, Magnes S, Popowski L, Gisolfi C. Accuracy of Urine Specific Gravity and Osmolality as Indicators of Hydration Status. Int J Sport Nutr Ex Metab. 2005;15(3):236

6. Oppliger R, Bartok C. Hydration testing of athletes. Sports Med. 2002;32(15):959-971.

7. Armstrong LE. Hydration assessment techniques. Nutr.Rev. 2005;63:30-54

8. Maughan RJ. Impact of mild dehydration on wellness and on exercise performance. Euro J Clin Nutr. 2003;2: 19-23

9. Minton D, Eberman L. Best practice for clinical hydration measurement. Athl Ther Today. 2009;14(1):9-11.

10. Greer F. Myth buster: Caffeine does not exhibit a diuretic effect during exercise performance. Indian J Med Res. 2010;132(1):11-13.

11. Goulet E. Review of the Effects of Glycerol-Containing Hyperhydration Solutions on Gastric Emptying and Intestinal Absorption in Humans and in Rats. Int J Sport Nutr Exerc Metab. 2009;19(5):547-560.

12. Artioli GG, Franchini E, Nicastro H, Sterkowicz S, Solis MY, Lancha AH. The need of weight management control program in judo: a proposal based on the successful case of wrestling. J Int Soc Sport Nutr. 2010,7:15

13. Casa D, Stearns R, Lopez R, Ganio MS, McDermott BP, Yergin SW, Yamamoto LM, Mazerolle SM, roti MW, Armstrong LE, Maresh CM. Influence of hydration on physiological function and performance during trail running in the heat. J Athl Train. 2010;45(2):147-156.

14. Walker EE. Weight cutting in wrestling, The effects of dehydration on wrestling performance and health. Sport Psyc. 2003,31:1-5 
15. National Wrestling Coaches Association. NWCA optimal performance calculator. NWCA Web site. Www.nwcaonline.com/nwcaonline/wrestling.aspx.

16. Kraemer WJ, Fry AC, Rubin MR, Triplett-Mcbride T, Gordon SE, Perry KL, Lynch JM, Volek JS, Meuffels DE, Newton RU, Fleck SJ. Physiological and performance responses to tournament wrestling. Med Sci Sport Exerc. 2001;33:1367-1378

17. Rankin, JW, Ocel JV, Craft LL. Effect of weight loss and refeeding diet composition on anaerobic performance in wrestlers. Med Sci Sport Exerc. 1996;28:1292-1299

18. Nichols JJ, Mitchell GL, Good GW. The reliability and validity of hand-held refractometry water content measures of hydrogel lenses. Opt Vis Sci. 2003;80:447-453

19. Stuempfle KJ, Drury DG. Comparison of 3 methods to assess urine specific gravity in collegiate wrestlers. J Athl Train. 2003;38(4)315-319

20. Casa DJ, Armstrong, LE, Hillman SK, Montain SJ, Reiff RV, Rich BS, Roberts WO, Stone JA. National athletic trainers' association position statement: fluid replacement for Athletes. J Athl Train. 2000;35(2)212-224

21. Ritz P, Berrut G. The importance of good hydration for day-to-day health. Nut Rev. 2005;63:S6-S13.

22. Perriello, Almquist, Conkwright, Cutter, Gregory, Pitrezzi, Roemmich, Snyders. Health and weight control management among wrestlers: a proposed program for high school athletes. Va Med Quart 1995;122(3): 179-185.

23. Iowa Gazette. Weight issues in wrestling. Iowa Gazette. Dec 22, 1997

24. Gould D, Eklund R, Petlichkoff L, Peterson K, Bump L. Psychological predictors of state anxiety and performance in age-group wrestlers. Pediatric Exercise Science. 1991;3:198208

25. Scanlan T, Lewthwaite R, Jackson B. Social psychological aspects of competition for male youth sport participants: II. Predictors of performance outcomes. J Sport Psyc. 1984;6(4):422-429.

26. Fogelholm M. Weight reduction and sport performance. Sports Med. 1994;18:240-267

27. Hickner RC, Horswill CA, Welker JM, Scott J, Roemmich JN, Costill DL. Test development for the study of physical performance in wrestlers following weight loss. Int J Sports Med. 1991;12(6)557-562 
28. Kraft J, Green J, Bishop P, Richardson M, Neggers Y, Leeper J. Impact of dehydration on a full body resistance exercise protocol. Euro J App Physiol. 2010;109(2):259-267.

29. Roemmich JN, Sinning WE. Weight loss and wrestling training: effects on nutrition, growth, maturation, body composition and strength. Appli Physio Resea Lab. 1997;82(6): 1751-1759. 
APPENDICES 


\section{APPENDIX A}

\section{THE PROBLEM}

Research Question

Dehydration is characterized and defined as "a dynamic loss of body water or the transition from euhydration to hypohydration". ${ }^{30}$ It is important for all athletes to be hydrated to ensure proper body function and to perform at peak capacity during competition. Proper hydration is necessary for facilitating recovery after activity and optimizing body regulatory factors. ${ }^{31}$ Hypohydration has been associated with an increase in core body temperature, cardiovascular strain, decreases in cardiac stroke volume and decreases in serum sodium levels.

${ }^{30}$ Hydration is extremely important not only to perform well during competition, but also in keeping the body functioning normally under stresses. Many athletes are not educated on proper hydration, fluid replacement practices, and the effects on performances, thus increasing the chances for heat related illness such as heat illness, heat syncope, and heat stroke. ${ }^{30}$ Dehydration as little as 2-3\% percent, which can be characterized as a loss of $2-3 \%$ percent of normal body weight; has numerous effects including cardiovascular function, low blood pressure, tachycardia, confusion, muscular weakness and ability to dissipate heat become impaired. These can greatly affect athletic performance and can even lead to kidney failure and coma in extreme cases ${ }^{5,8,21}$ The various health problems that can arise from dehydration should be communicated to athletes. Athletes need to have the knowledge and understanding regarding the negative effects of intentional dehydration including those effects on performance.

It is required in many sports including wrestling, boxing, martial arts, and lightweight crew that specific weight be maintained to participate in a certain weight class. ${ }^{1,5}$ In wrestling there are different weight classes in which athletes compete. The fastest way for many athletes 
to lose unwanted weight, in order to reach a desired weight class is through intentional dehydration. Various referred journal articles have documented that there are detrimental physical side effects for athletes who attempt to lose large amounts of weight in a short time period. Being in a dehydrated state can cause injuries and those injuries may result in a loss of game or practice time for up to $1 \%$ of all athletes. ${ }^{32}$ In 1997,3 college wrestlers died after attempting to drop over $15 \%$ of their body weight in one week by intentional dehydration and other dangerous practices. ${ }^{1,2,5,33}$ It is for these reasons that the National Collegiate Athletic Association (NCAA) and the National Federation of State High School Associations (NFSHSA) developed the Optimal Performance Calculator to limit the amount of weight a wrestler can lose per week safely based on preseason body weight and body fat percentage in a euhydrated state. It is important for wrestlers to remain hydrated throughout the season while attempting to reach their competition weight classes without the detrimental effects of intentional dehydration. Currently the NCAA and the NFSHSA require that wrestlers are tested yearly to become certified to compete in a certain weight class. ${ }^{1,2,5}$ This hydration testing helps to minimize the potential risks of intentional dehydration by only allowing the wrestler to compete in specific weight classes by certain dates and also creates a minimum weight class that the wrestler can reach. These restrictions are based on body fat percentages and weight that is measured during a euhydrated state for each wrestler to determine a safe "goal competition weight" and a safe weight loss plan. ${ }^{15}$ Athletes will continue to intentionally dehydrate putting their personal health at risk as well as their overall success to gain an advantage. However the perceived advantage may actually have detrimental effects on overall performance.

High school athletes' bodies are still developing, so it is important to receive the proper nutrition and also maintain normal levels of body water. If dehydration poses a health and 
performance risk for older, collegiate athletes, it is therefore inferred that the younger high school athletes posses an even greater risk of incurring bodily harm as well as decreases in performance. It is important to observe how dehydration can affect an athletes' performance throughout a season.

Performance is typically measured by how well one does in a competition. To date there is no accurate way to directly measure overall performance in a wrestler during a match. However team points are awarded to an individual wrestler based on the outcome of a match whether it is a decision, major decision, technical fall, or pin fall. The more points the wrestler scores over his opponent, the more team points earned up to a maximum of 6 team points for a pin fall. This is how teams win dual meets and tournaments. Performances and team points vary from each match and the more hydrated the wrestler, the better performance may be on the mat. The fact remains, unfortunately, that many athletes still perceive an advantage that may be gained from cutting weight to reach a lower weight class by using dangerous methods that can hurt their bodies and their performances. Thus the questions presented are, 1) is there a difference between hydration levels over three time points between a high specific gravity group and a low specific gravity group; 2) do those who have the lowest average specific gravity have a higher win percentage and; 3) do those who have a lower average specific gravity earn more team points throughout a season.

Experimental Hypothesis

1. There will be a difference between a wrestler's baseline and specific gravity throughout the season between groups. Wrestlers will be more dehydrated during the season as compared to baseline results.

2. Wrestlers in Group 1 who have the lower average specific gravity will have a higher win percentage that those in Group 2. 
3. Wrestlers in Group 1with high average specific gravity values will score significantly less team points throughout the season.

\section{Assumptions}

1. All subjects will complete the research study in its entirety.

2. All scales and refractometer will be calibrated accurately.

3. All data will be confidential.

4. Subjects will follow protocol set by researcher for all measurements.

5. Starters will compete in $75 \%$ of all competitions

Delimitations

1. Results cannot be generalized because the only subjects used were high school wrestlers from a high school in Western Pennsylvania.

Operational Definitions

1. Average Specific Gravity- (Specific gravity value for 24 hour pre-competition $1+2+3+\ldots 12) / 12$ and (Specific gravity value for pre-competition $1+2+3+\ldots 12) / 12$

2. Cardiac Stroke Volume- Increased heart rate which decreases the amount of filling time in the ventricular chambers. This leads to lower amounts of blood being pumped through the body. 13

3. Decision- A wrestler wins a match by a margin of less than 8 points. This results in 3 team points. ${ }^{34}$

4. Default- The wrestler is unable to continue competition due to injury, illness, etc. This results in 6 team points. ${ }^{34}$

5. Dehydration- A dynamic loss of body water, or the transition from euhydration to hypohydration. ${ }^{30}$

6. Disqualification- Wrestler is banned from participating further in a match by acquiring penalties or for flagrant misconduct. This results in 6 team points. ${ }^{34}$

7. Diuretics- A method of weight loss that increases the body's production of urine.

8. Euhydrated- Normal body-water content, sometimes based on bodyweight if it stays within $0.45 \mathrm{~kg}$ day to day, a fluid intake which allows for normal urine volume and 
concentration, a relatively stable level of intracellular and extracellular body water, and a normal blood chemistry make up. ${ }^{5}$

9. Forfeit- The wrestler fails to appear for the match. This results in 6 team points. ${ }^{34}$

10. High Specific Gravity Group- Subjects placed in group if average specific gravity is $>1.020$.

11. Hyperosmolality- Increased osmotic concentration of a solution, sodium in cellular water.

12. Hyperthermia- An increase in core body temperature. ${ }^{13}$

13. Hypohydration- A body-water deficit.

14. Hypovolemia- A decrease in blood volume, specifically blood plasma. ${ }^{13}$

15. Lange-Skin Fold Caliper- A scientific instrument designed to measure body fat through a sub-cutaneous tissue measurement; sites used are triceps, sub-scapular, and abdominal.

16. Low Specific Gravity Group- Subjects placed in group if average specific gravity is $\leq 1.020$.

17. Major Decision- A wrestler wins a match by a margin of 8 or more points, but under 15 points. This results in 4 team points. ${ }^{34}$

18. Minimum Wrestling Weight- Lowest allowable weight one can wrestle at determined by $7 \%$ body fat for males and $12 \%$ body fat for females. ${ }^{15}$

19. Physiological Performance- The ability to perform at peak capacity, measurements include aerobic and anaerobic outputs.

20. Pin- Occurs when one wrestler holds any part of both the opponent's shoulders or both of the opponent's scapula in continuous contact with the mat for one second. This immediately ends the match and results in 6 team points. ${ }^{34}$

21. Refractometer- A scientific device used to test the specific gravity of urine.

22. Team Points- subject 1 total team points + subject 2 total team points...+ subject 6 total team points)/ total number of subjects in the group

23. Technical fall- When a wrestler secures an advantage of 15 points over an opponent, this immediately ends the match and results in 5 team points. ${ }^{34}$ 
24. Urine Specific Gravity- Used to determine minimum wrestling weight. It is measured by a refractometer. If specific gravity is above 1.025 the athlete is considered to be in a dehydrated state. ${ }^{9,15}$

25. Wingate Test- A test performed on a stationary bike used to measure peak anaerobic power, anaerobic fatigue and total anaerobic capacity. ${ }^{17}$

26. Win Percentage- (Total \# of wins/ Total \# of matches) $x 100$

27. Wrestling Performance- Peak performance is characterized by the ability to win a match over an opponent. Wins are given team points based on how many individual points were earned or the outcome of the match. Generally the more individual points earned the more team points earned.

Limitations

1. Threats to internal validity include history, maturation, pre-testing, and mortality. Since the study is longitudinal it is possible that certain events may occur that could influence the study. Maturation of subjects can occur throughout the testing period by physical growth and mental and emotional development. All subjects must perform a state required pre-test in November that is identical to the follow up tests they will perform. Mortality may also occur due to an athlete becoming injured, quitting the team, or possibly a change in the starting rotation.

2. Threats to external validity include selection of subjects and the generalization of results because this study is reserved to a sample of convenience using high school wrestlers at a high school in western Pennsylvania and cannot be generalized throughout the population since subjects from other schools were not used.

Significance of the Study

This study has significance not only to wrestlers but to all athletes. Hydration is important to both maximizing performance and also to help minimize certain injuries.

Dehydration has been linked as a cause of many injuries and has resulted in a loss of game or practice time for up to $1 \%$ of all athletes. ${ }^{32}$ Through measuring the athletes' hydration level over time and comparing it to performance during competition it will indicate how important it is to maintain a euhydrated state. This will educate athletes on how important hydration is and to realize how important it is to not intentionally dehydrate for weight loss. 
Wrestlers are notorious for using risky methods to drop weight. These include restricting food and fluid consumption and in some cases wearing vapor-impermeable suits underneath cotton sweat suits and exercising intensely in hot environments. ${ }^{35}$ The quickest and possibly most dangerous is the act of intentionally dehydrating before competition. The most aggressive timeframe for this dehydration is $24-48$ hours before a competition. ${ }^{35}$ If this study can educate athletes on how hydration can increase performance and how dehydration can decrease performance, some athletes may be persuaded against performing risky weight loss practices.

All information will be presented to athletes, coaches, and parents at the conclusion of the regular wrestling season in a presentation. To reach a broader audience, publication in the Journal of Athletic Training is important for the athletic training community in hope that athletes, coaches, and athletic trainers can be better educated on the importance of hydration and how dehydration can negatively affect performance. These results can benefit everyone involved in sports that athletes must manage weight to compete in pre-determined weight classes throughout the season. 


\section{APPENDIX B}

\section{LITERATURE REVIEW}

Introduction

Every athlete wants to perform to their maximum during competition. In wrestling many athletes believe that if they are able to compete in a lower weight class than their normal body weight they can gain an advantage over their opponents. They believe they will be faster and stronger and therefore be able to outperform the competition. ${ }^{1,2,3}$ All too often though athletes will hurt their overall performances by attempting to drop too much weight too quickly and are competing in a dehydrated state. Numerous physiological and psychological problems develop when the body is only slightly dehydrated and performances can be hindered. ${ }^{8,10,11,12,13}$

Unfortunately in 1997 three wrestlers died while attempting to drop a large amount of weight through intentional dehydration practices and increasing exercise intensity and frequency. ${ }^{6,7}$ For these reasons and multiple other incidences the NCAA implemented required hydration and body fat testing at the beginning of the season which set individual minimum wrestling weights and maximum amounts of weight loss per week. ${ }^{34}$ High school organizations soon followed suit and now all high school wrestlers are required to be tested and certified at the beginning of each season. ${ }^{15}$

This thesis provides a literature review of what classifies euhydration and dehydration in the body. Also discussed will be common practices and techniques that wrestlers employ to cut excess weight while attempting to compete in a lower weight class. Furthermore, how dehydration can affect performance and how individual performance can be measured during competition will be included. Finally, hydration testing will be reviewed to determine which method is the most practical to accurately and safely measure hydration status in athletes. 
Euhydration vs. Dehydration

Water makes up roughly $60-70 \%$ of overall body mass in males and $50-55 \%$ of body mass in females. ${ }^{8,9}$, There is no definitive number that is placed on the body to be considered euhydrated but there is a criterion that has been used to determine if one is in a euhydrated state for some studies. Oppliger et al. ${ }^{5}$ stated that to be euhydrated, bodyweight must stay within $0.45 \mathrm{~kg}$ day to day, a fluid intake for normal urine volume and concentration, a relatively stable level of intracellular and extracellular body water exists, and a normal blood chemistry make up. ${ }^{5}$ It has been noted though that for one to have a detrimental effect on cardiovascular status, heat dissipation and athletic performance, a 2-3\% level of dehydration is evident. ${ }^{8}$ Many involved in sports medicine categorize dehydration as the amount of weight lost during a diurnal cycle.

Meaning if the athlete loses $3 \%$ of their bodyweight they are thought to be $3 \%$ dehydrated. ${ }^{5,13}$ There are many different types of dehydration such as hypertonic dehydration, isotonic dehydration, and hypotonic dehydration. Hypertonic is classified by blood hypernatremia and hyperosmolarity and a decrease in plasma volume. ${ }^{36}$ This is seen mostly after exercise. Isotonic dehydration occurs when water and sodium loss occurs usually as a result of fasting or vomiting, and blood and urine components appear normal. ${ }^{36}$ Hypotonic dehydration results when sodium ingestion is restricted and if diuretic drugs or caffeine are taken. ${ }^{10}$ This presents as low serum sodium and osmolality. ${ }^{36}$ In a hypertonic state more sodium is retained than water which in turn leads cells to decrease the amount of intracellular water. This allows for homeostasis within the cell. However this also leads to the cell shrinking. Once the cells begin to shrink they lose their ability to function at full capacity. ${ }^{37}$ When the cells are unable to function normally the body cannot and thus overall performance will decrease. 
Determining Hydration Status to Avoid Excessive Weight Loss

As many as $80-90 \%{ }^{12,14}$ of wrestlers practice some form of weight loss techniques to drop to the lowest weight class possible in order to obtain a perceived advantage over opponents. It is believed that if one is in a weight class lower than normal body weight they will be stronger, have leverage advantages, and may even be faster than others. ${ }^{1,2,3}$ Traditionally dropping a few pounds will not cause many physiologic problems but a study by Nitzke, et al. ${ }^{38}$ has shown that mean weight loss for one week in college wrestlers averaged 13 pounds over a season. ${ }^{38}$ There are many techniques that wrestlers use to "cut weight". Typically these include intentional dehydration, dieting, diuretics or other drugs, and increasing intensity or frequency of exercise. ${ }^{1,5}$ Nearly $80 \%$ of college wrestler use dieting, over $50 \%$ simple fasting and $75 \%$ increase their exercise routine. ${ }^{5}$ Many athletes use multiple techniques which allow for a very rapid weight loss. ${ }^{1}$ It is well documented that many wrestlers are using the techniques in an unsafe manner and in 1997 three college wrestlers died after attempting to lose up to $15 \%$ of their bodyweight in one week through fasting and dehydration. ${ }^{6,7}$ This incident, along with others, prompted the National Wrestling Coaches Association (NWCA), the National Collegiate Athletic Association (NCAA) and the National Federation of State High School Associations (NFSHSA) to implement new weight management rules. These new rules were intended to reduce the amount of weight wrestlers were attempting to drop and to improve nutrition and overall health of high school and college wrestlers. ${ }^{15}$

Currently every wrestler must be assessed at the beginning of each season with a hydration assessment test and be registered online. Urine specific gravity to assess current hydration status as measured by a refractometer, body composition at three skin fold sites measured by a Lange Skin Fold caliper, and weight to within 0.1 pounds are used. These results 
are then entered into an online computer program and minimum wrestling weight is established. According to the NWCA the wrestler must have a urine specific gravity of less than 1.025 to be considered in a hydrated state. If the wrestler does not pass the urine specific gravity test, certification is not obtained that day and at least a 24 hour waiting period must exist before the hydration test is retaken. This test does not allow the wrestler to drop more than $1.5 \%$ of their body weight each week until reaching minimum wrestling weight, determined by $7 \%$ body fat for males and $12 \%$ body fat for females. ${ }^{15}$ This lowers the risk of wrestlers attempting to quickly drop large amounts of weight in a short period of time. Wrestlers are required to lose weight slowly if they choose to do it at all. At a competition each coach is required to have a current list of each wrestler participating in the competition with each athletes predetermined allowable wrestling weight and weight class as well as their minimum wrestling weight. A wrestler can be disqualified from a competition if the wrestler attempts to weigh-in at a lower weight class. Unfortunately many wrestlers do not adhere to the guidelines and will spend the last two to three days before each competition attempting to drop weight gained between the previous competition and the upcoming one through dangerous rapid weight loss techniques such as intentional dehydration. Studies show in young adults that restricting fluids even without restricting food resulted in a deficiency of $2.7 \mathrm{~L}$ of body water over a 37 hour time period. After 24 hours there was a loss of body weight of $1.8 \%$ and after 37 hours a body weight loss of $2.7 \%$. ${ }^{21}$ This 37 hour window is about the same time that many wrestlers attempt to lose large amounts of weight quickly through rapid weight loss practices.

Dehydration and Performance

Even when an athlete becomes dehydrated around 2-3\%, physiological problems begin to occur and as a result cause deficits in performance. When an athlete loses $2 \%$ of their body 
mass (become $2 \%$ dehydrated) a physiological stress is placed on the body which causes hyperthermia, or an increase in overall core body temperature by $0.12^{\circ} \mathrm{C}$ to $0.25^{\circ} \mathrm{C}$. Heart rate also increases about 3 to 5 beats per minute. ${ }^{10,13,20}$ At a $5 \%$ dehydrated state muscular strength and overall power is decreased significantly. ${ }^{10,20}$ In one study these results were not supported. Hypohydrated athletes showed a decrease in single-leg knee endurance exercise time in a temperate condition. However there was no evidence from this study to support the decreases in performance as a result of muscle glycogen utilization as is previously thought. Instead the overall decrease in performance was documented as a result of thermoregulation and that an increase in core temperature mediated by a body water deficit was to blame. ${ }^{39}$ Another study by Goulet ${ }^{11}$ found that sub-maximal efforts were affected due to the decreasing glycogen utilization within the recruited muscles. However these studies ${ }^{11,39}$ evaluated different aspects of muscular performance, Goulet at sub-maximal efforts and Sawka at endurance. Muscle glycogen utilization could be affected differently depending on the type of output required for a certain activity

As the athlete continues to exercise or intentionally dehydrate they continue to lose body water. When dehydrated the ability to dissipate heat by increasing core temperature is reduced. The more dehydrated, the higher core temperature may rise, and the ability to dissipate heat continues to decrease. Dehydration also causes other physiological problems such as a decrease in cardiac stroke volume ${ }^{10,11,12}$ caused by the increased heart rate which decreases the amount of filling time in the ventricular chambers. ${ }^{13}$ Also the stress response, perception of effort given and anticipatory regulation of pace, hypovolemia, hyperosmolality, and a decrease in overall work completed are also affected by dehydration. ${ }^{13}$ Dehydration can have an effect on the psychological perception as well as physiological responses to competition. 
Fogelholm ${ }^{26}$ reported in a study that aerobic capacity decreases with dehydration especially when subjects were using diuretics in conjunction with rapid weight loss. This was also reported in a study by Hickner et al. ${ }^{27}$ who confirmed a decrease in aerobic capacity when athletes were in a dehydrated state. However, some studies have reported that there is no significant decrease in maximum oxygen uptake $\left(\mathrm{VO}_{2} \max \right)$ after rapid weight loss. ${ }^{40}$

Many athletes believe that caffeine can increase performance by providing an ergogenic effect. In fact consumption of caffeine before competition or as a way to increase weight loss can have negative effects on the body. Caffeine causes a diuretic affect and also stimulates the sympathetic nervous system which results in an increase of sweat rate, further exacerbating dehydration. ${ }^{10}$ Some studies ${ }^{10,41}$ have found however that caffeine, when used in hot or humid conditions, often indicative of a wrestling practice room, does not have a substantial effect on overall dehydration at the time.

Overall muscular strength can also be affected by dehydration. In a study by Kraft et al. ${ }^{28}$ subjects were tested for muscular strength, using overall upper body program of three sets to failure, in a 3\% dehydrated state. Their results showed that in only a 3\% dehydrated state the subjects showed a significant decrease in the amount of repetitions performed. It was also shown that heart rate was generally higher when tested in a dehydrated state and also showed a longer recovery time required to return to resting pace. Many studies ${ }^{13,14}$, have shown that dehydration affects maximal force output but not many have shown how it can affect muscular endurance. In wrestling both maximal forces ${ }^{14}$ as well as endurance are important. However, endurance can be argued as more important based on the amount of time the wrestlers are required to perform aerobic and anaerobic exercises during a six minute match. It should be no surprise that if a wrestler suffers a decrease in sub-maximal muscular contraction when 3\% dehydrated, that sub- 
maximal muscular contraction will decrease exponentially if further dehydrated. This can often occur when wrestlers are attempting to cut weight and lose more than $3 \%$ of body weight, sometimes in a very short amount of time. It is critical not only for health, but also for ability to perform to the utmost capacity that wrestlers be properly hydrated during competition and practices.

Wrestling Performance

When using rapid weight loss techniques there can be negative consequences to both health and performance. In a study by Artioli et al. ${ }^{12}$ at least 3-4 hours of recovery is necessary for athletes to typically be able to return to normal values for hydration, if allowed to eat and drink as much as they want. However, most competitions do not allow for this amount of time between weigh-ins and the first match. During dual meets wrestlers can be weighed in at a maximum of one hour before the meet begins. During tournaments weigh-ins must be completed within 2 hours of the first match and 1 hour before the first match on subsequent days. ${ }^{34}$ Athletes are given some time to recover and consume fluids between weigh-ins and match time, but not enough to return to normal, euhydrated values as described in other studies. ${ }^{12}$ It may take 24-48 hours to reestablish fluid homeostasis, ${ }^{42}$ and up to 72 hours to replenish muscle glycogen stores. ${ }^{4}$ When matches begin, if the wrestler is in a dehydrated or severely dehydrated state performance will be affected. If dehydration affects performance there will not be an adequate time frame enabling the wrestler to regain a euhydrated state.

To date there are very few studies that directly measure wrestling performance based on wins and losses. It is typically considered a subjective measurement as there are many factors involved in a win or loss of a match. Previous experience, mental capacity, attitude, overall skill, strength, as well as physiological components are just a few factors that can contribute to a win 
or loss. Many of these cannot be accurately measured on an objective scale. Wins and losses however can be measured and how the individual won the match is also measured on an objective scale. In a study by Treasure et al. ${ }^{43}$ self-efficacy was measured and compared to wrestling performance. Subjects were given a questionnaire about perceptions of self-efficacy, anxiety and positive and negative affect pre-competition. Performance was measured in two ways. The first was the overall outcome of the match recorded as a win or a loss. The second was to use the point-scoring system that provides points for successful or unsuccessful execution of wrestling skills during a competitive match. ${ }^{43}$ Other studies ${ }^{24,25}$ have also used wins and losses as an indicator of performance. In a study by Gould ${ }^{24}$, he examined how psychological factors correlate to match performance. He measured pre-competition expectations and anxiety ten to twenty minutes before the first two rounds of a tournament. Immediately after the match he measured satisfaction and anxiety again and discovered that those subjects who had more years of experience and a higher pre-competition expectation score performed the best and had higher win percentages. Scanlan ${ }^{25}$ performed a similar study, but focused on enjoyment of the sport and the outcome of the first two rounds of a wrestling tournament. He found that those who generally enjoyed the sport more, along with other factors such as parental satisfaction, parental pressure, and positive adult involvement, performed best compared to other subjects.

At the end of a match a wrestler's team is awarded team points based on the result of the individual match. For instance if a wrestler wins a match by a margin of less than 8 points, the team receives 3 team points for a decision. A win of between 8-14 points over an opponent is considered a major decision and the team will receive 4 team points. Securing a technical fall requires an advantage of 15 or more points over the opponent to receive 5 team points. If the wrestler is able to pin the opponent, granted a forfeit (the opponent does not appear for the 
match), a default (the wrestler is unable to continue the match due to injury, illness, etc.), or a disqualification of the opponent; the team is granted 6 team points. If a wrestler loses a match 0 team points are granted. In a dual meet between 2 teams the team with the most team points is considered the winner of the dual. ${ }^{34,44}$ Consequently team A may win more matches but only by narrow margins earning less team points per match, team B could have performed better, such as defeating an opponent by pin fall, in certain matches earning larger numbers of team points. Therefore an individual's performance will be measured by team points earned and also overall win/loss percentages. Losses will be measured in a negative scale by tracking how the wrestler was beaten. Wrestlers will receive -4 points for a major decision loss, -6 points for being defeated by a pin fall, and so on.

Other studies typically measured anaerobic or peak power output ${ }^{17}$ by a Wingate or other test, or overall upper or lower body strength. ${ }^{16}$ The stresses induced during a competitive match can aggravate any conditions the athlete experiences. Unfortunately, to our knowledge there is no way to accurately measure performance during a match, so the outcome of the match must be used. A win is no doubt a better performance than a loss, and a pin during a match, as agreed by most coaches and athletes, constitutes a better performance than winning by a single point. Hydration Testing

There are many different ways hydration status can be measured in athletes. Some of the most common are urine specific gravity tests, urine color, urine osmolality and plasma osmolality. ${ }^{9}$ Like many tests each of these has different positives and negatives. The most accurate and reliable tests can be expensive and require a lab to perform. While others are less expensive and relatively easy to perform, these are often used in a clinical setting. It is best for one in a clinical setting to use an inexpensive yet practical tool that also is reliable and accurate. 
A refractometer, measuring specific urine gravity is often the best tool to use in these situations as it is reliable, accurate, and requires very little training for one to become proficient. ${ }^{9} \mathrm{~A}$ refractometer has a validity of $.97{ }^{18}$ reliability of $.998 .{ }^{19}$ Refractometers are used to measure the ratio between the density of urine and the density of water. According to the National Athletic Trainers Association position statement on fluid replacement, an average value for one who is minimally dehydrated is between 1.010 and 1.020. One who is significantly dehydrated specific gravity will be between 1.021 and 1.030 . When specific gravity is above 1.030 the athlete is seriously dehydrated (Table B1). These values were determined by using blood tests and having known dehydration values based on body weight changes for various subjects. ${ }^{9,20,45}$

Table B1. Indexes of Hydration Status ${ }^{20}$

\begin{tabular}{lccc}
\hline \multicolumn{4}{c}{$\%$ Body Weight } \\
Condition & Change & Urine Color & USG \\
\hline Well Hydrated & +1 to -1 & 1 or 2 & $<1.010$ \\
Minimal Dehydration & -1 to -3 & 3 or 4 & $1.010-1.020$ \\
Significant & -3 to -5 & 5 or 6 & $1.021-1.030$ \\
$\quad$ Dehydration & & & \\
Serious Dehydration & $>5$ & $>6$ & $>1.030$ \\
\hline
\end{tabular}

In order for a wrestler to pass the preseason hydration test, and to be certified they must have a hydration value of 1.025 or less. The NCAA, NFSHSA and NWCA accept this method to provide an athletic trainer or physician with an accurate hydration measurement to certify an athlete to participate in a certain weight class. It is non-invasive as it only requires a small amount of urine, can be performed very quickly and very inexpensive while still providing reliable results. Refractometer measurements are the preferred way to measure urine specific gravity. ${ }^{9,12}$

Another form of measuring urine specific gravity is by using urine reagent strips which is considered by some researchers to be just as effective and reliable as refractometer 
measurements. One study found that urine reagent strips are highly unreliable and recommended that the only reliable method to accurately measure specific gravity is by refractometer. ${ }^{46}$ In a study by Stuempfle and Drury ${ }^{19}$ three methods were used to assess urine specific gravity in college wrestlers. Refractometer, hydrometry, and urine reagent strips were all used. Results showed that hydrometry had a $28 \%$ false positive and a $2 \%$ false negative. While urine reagent strips had a $15 \%$ false positive and a $9 \%$ false negative and both showed significantly higher specific gravity readings compared to a refractometer. The study concluded that refractometer should be the only way to determine specific gravity in collegiate wrestlers. ${ }^{19}$ Measuring overall body mass can be used to measure hydration status but is often seen as unreliable over long time periods because it does not account for changes in body fat masses. ${ }^{7}$ Urine color can be a quick and easy way for someone to determine if they are hydrated or need to consume more fluids. Currently there is a numbered scale that ranges from 1-8. The lowest level, level 1, specifies urine color at a very pale yellow, while the highest, level 8, rates urine color as a brownish green. Those who can maintain a pale yellow urine color over time have been found to be within $1 \%$ of their euhydrated state. ${ }^{7}$ This test does not provide a specific or accurate number and is simply a visual check and hence urine color is not accurate enough to truly measure hydration status.

There are new devices and methods being devised to accurately measure hydration status while still attempting to be easy and practical to use. Two of these methods are urine conductivity analyzer which takes a urine sample and tests the electrical conductivity of the urine to analyze water levels within the urine. The other is arm radio frequency absorption which uses electromagnetic waves that interact with body tissues, water, and different solutes and measures the differences in these waves throughout exercise. ${ }^{7}$ These new methods are still in development and are not suggested for use to measure specific gravity in the clinical setting due to cost and 
specialized equipment required. It is recommended by many researchers to utilize an accurate, safe, and inexpensive method to measure an athlete's hydration status. Many researchers conclude that urine specific gravity, urine color, and body mass meet these requirements the best. 7, 47, 48 The best option for most because of the ease of use, low expense of materials needed, and how non-invasive the procedure is, is to use a refractometer to measure specific urine gravity. Summary

Despite rule changes over the years and continuing education of high school and college wrestlers many athletes are still performing dangerous weight loss practices which can lead to damaging a wrestler's health as well as the wrestler's performance on the mat. Water constitutes a large majority of body mass in people. It is vital for proper body and cellular function to be in a euhydrated state. At around 2-3\% dehydrated there is a decrease in physiological activity throughout the body. Wrestlers often are competing in a dehydrated state exceeding 2 or $3 \%$. Unfortunately attempts to drop weight very rapidly rely on using practices such as fluid restriction, food restriction, diuretics or other drugs, increasing exercise intensity and frequency, rubber suits, and various other harmful practices have been reported. Most wrestlers have used intentional dehydration practices to quickly cut excess weight to reach a lower weight class. The NCAA, NFSHSA, and NWCA have implemented the optimal performance calculator and minimum wrestling weights to limit the amount of weight a wrestler can lose each week and overall for the season.

Performances can be greatly affected by only mild dehydration. At a $2 \%$ dehydrated state core body temperature rises and heart rate increase. Cardiac stroke volume is decreased, ability to dissipate heat decreases, and multiple psychological problems occur including perception of effort and regulation of pace. At 3-5\% dehydrated significant muscular strength, 
power, and endurance are lost. When the body is given time to recover from a dehydrated state normal homeostatic levels are reached within 3-4 hours. Wrestlers are typically given only an hour or two between weighing-in and the start of the first match thereby affecting performance. Although performance is difficult to measure, team points earned from the individuals match can be used to determine competitive level of performance.

There are many different ways to determine hydration status. Some require blood samples but most require non-invasive urine samples. The NCAA, NFSHSA, and NWCA recommend that the best solution to accurately, safely, inexpensively, and most non-invasive way to measure hydration status is specific urine gravity measured by a refractometer. 
APPENDIX C

ADDITIONAL METHODS

Table C1. Informed Consent

PARENTAL OR GUARDIAN CONSENT AND INFORMATION FORM

Principal Investigator: Sandrey, Michelle

Department: College of Physical Activity and Sport Sciences

Study Title:

Does Hydration Affect Performance and Win Percentages of High School Wrestlers?

Co-Investigator(s):

Brausch, Joseph

\section{Contact Persons}

In the event your child experiences any side effects of injury related to this research, you should contact Joseph M. Brausch, ATC at (513) 659-3935 or at JBrausch@mix.wvu.edu. If you have any questions, concerns, or complaints about this research you can contact Dr. Michelle A. Sandrey, PhD, ATC at (304) 293-0870 or at msandrey@mail.wvu.edu. For information regarding my rights as a research subject, I may contact the Executive Secretary of the Review board at (304) 293-7073.

\section{$\underline{\text { Introduction }}$}

You, , have been asked to allow your child to participate in this research study, which has been explained to you and your child by Joseph M. Brausch, ATC. This study is being conducted by principal investigator Michelle Sandrey, $\mathrm{PhD}, \mathrm{ATC}$ and the co-investigator Joseph M. Brausch, ATC. This research is being conducted to fulfill the requirements for a master's thesis in athletic training in the College of Physical Activity and Sport Sciences at West Virginia University, under the supervision of Dr. Michelle A. Sandrey $\mathrm{PhD}, \mathrm{ATC}$.

\section{Purpose of the Study}

The purposes of the study are to determine if 1) there is a difference between varying hydration levels over 24 hours from baseline, 2) do those who have the lowest average specific gravity perform better by having a higher win percentage and, 3) do those with higher average levels of hydration perform better by earning more team points in matches. WVU expects to enroll approximately 20 subjects in this study 


\section{$\underline{\text { Description of Procedures }}$}

The study will be conducted at Albert Gallatin High School, 1119 Township Dr Uniontown, PA 15401. All testing procedures will be performed in the Albert Gallatin Wrestling team's locker room and coaches office at Albert Gallatin High School. There is also a private restroom in the coaches office where samples will be given. Your child will be asked to perform a hydration test much like the state mandated test required at the beginning of the season. The major difference will be that no body fat analysis will be conducted. Your child will be placed into one of two groups based on their competition history throughout the season. The intervention group will be decided by those wrestlers that compete in at least $75 \%$ of competitions. Those not included in the intervention group will be in a control group to compare results to. If you and your child choose to participate your child will be asked to provide a small urine sample and weigh in the day before a competition and then again the day of the competition. This will be done multiple times throughout the regular season. There are 12 competitions scheduled this year so your child will be tested 24 times. Once 24 hours before a competition and again the day of the competition. These specific gravity measurements will show how hydrated your child is and will place them into one of two groups, a high average specific gravity group and a low specific gravity group. These groups will be compared to each other in regards to win percentage and also in regards to team points. We will investigate to see if hydration, measured by specific gravity, has an effect on win percentage and team points earned per match and thus on your child's performance.

If you and your child choose to participate, your child will be contacted by the co-investigator on various occasions to perform the testing procedures. These dates are subject to change due to changes in the regular wrestling schedule. I understand that there specific testing procedures to be followed. I understand that the only person to know my child's results and to record my child's results will be Joseph M. Brausch, ATC and that your child will be identified as a number during the course of the study to protect my child's personal and private information.

\section{$\underline{\text { Risks and Discomforts }}$}

You understand that your child may experience some mental discomfort or anxiety; however your child nor anyone other than the researcher will not know their specific gravity during the testing. I understand that there are minimal risks while performing the hydration test. The coinvestigator will maintain a safe, private environment during the hydration test. I am aware that a male recorder will be present for all males performing the test and a female will be present for any females performing the hydration test. I understand that every precaution has been taken to prevent your child from being injured during the hydration test. Should any injury occur, I understand that Joseph M. Brausch, ATC will provide first aid and will make any necessary referrals. 


\section{$\underline{\text { Alternatives }}$}

Your child does not have to participate in this study. The normal alternative is to participate in wrestling practices and competitions without the hydration tests throughout the season.

\section{$\underline{\text { Benefits }}$}

Your child may receive benefits from this study if they participate. Benefits include knowledge gained from the study on how hydration may affect their performance. Additionally the knowledge gained from this study may benefit other wrestlers.

\section{Financial Considerations}

If your child is injured while participating in this study you will be responsible for the cost of care provided. You understand that your child will not receive any monetary compensation for participation in this study.

\section{Confidentially}

Subjects Name:

ID Number:

We know that information about your child and your child's health is private. We are dedicated to protecting the privacy of that information. Because of this promise, we must get your written authorization (permission) before we may use or disclose your child's protected health information or share it with others for research purposes. The form gives that permission. It also helps us make sure that you are correctly told how this information will be used or disclosed. Please read the information below carefully before signing this form. Please ask any questions you may have about this form or its uses. You can decide to sign or not to sign this authorization form. However, if you choose not to sign the authorization form, your child will not be able to take part in the research study. Whatever choice you make about this research study, it will not have an effect on your access to medical care.

\section{USE AND DISCLOSURE COVERED BY THIS AUTHORIZATION. DO NOT SIGN A} BLANK FORM. You or your authorized representative should thoroughly read the information below before signing this form. This form will authorize the following person(s), class(es) of persons, and/or organization(s) to disclose, use, and receive the information: WVU, Michelle A. Sandrey, PhD., ATC, Joseph M. Brausch, ATC. The research site(s) carrying out this study includes WVU and Albert Gallatin High School. It also includes each site's research staff and medical staff. Health care providers who provide services to you as part of this research study include Joseph M. Brausch, ATC. If, during the course of the research, the institution listed above merges with, or is purchased by, another company or institution, this authorization to use or disclose protected health information in the research will extend to the successor company or institution.

SPECIFIC UNDERSTANDINGS: By signing this research authorization form, you give permission for the use and/or disclosure of your child's protected health information described 
above. The purpose for the uses and disclosures you are authorizing is to carry out the research study explained to you during the informed consent process. It is also to ensure that the information relating to the research is available to all parties who may need it for research purposes. Your child's protected health information may be used as necessary for your research-related treatment. This information may be re-disclosed or used for other purposes if a recipient described in this form is not required by law to protect the privacy of the information. You have a right to refuse to sign this authorization. Your child's health care outside the study, the payment for your child's health care, and your child's health care benefits will NOT be affected if you do not sign this form. However your child will NOT be able to take part in the research study described in this authorization if you do not sign this form. If you sign this authorization, you will have the right to cancel it at anytime, except to the extent that WVU has already taken action based upon your authorization or needs the information to complete analysis and reports of data for this research study. To cancel this authorization, please write to the Principal Investigator, Michelle A. Sandrey, Ph.D, at: West Virginia University, PO box 6116, Morgantown, WV 26505. You will NOT be allowed to see or copy the information described on this form as long as the research is in progress, but you have a right to see and copy the information upon completion of the research in accordance with hospital policies. You have a right to receive a copy of this form after you have signed it. Expiration Date: NONE

In any publication that results from this research, neither your child's name nor any information from which your child might be identified will be published without your consent.

YOUR CHILD OR YOUR CHILD'S AUTHORIZED REPRESENTATIVE MUST BE PROVIDED WITH A COPY OF THIS FORM AFTER IT HAS BEEN SIGNED.

SIGNATURE:

I have read this form and all of my questions about this form have been answered. By signing below, I acknowledge that I have read and accept all of the above

Signature of subject or

Authorized Representative:

Date:

Print Name of Individual Explaining this Research Authorization form

Address:

Telephone:____ (Daytime)

(Evening)

E-mail Address (optional): 


\section{Voluntary Participation}

Your child's participation in this study is voluntary. You are free to withdraw your consent for your child to participate in this study at any time. Refusal to participate or withdrawal will not affect your child's future care, class standing, or grades and will involve no penalty to you. In the event that new information becomes available that may affect your willingness for your child to participate in this study, this information will be given to you so that you can make an informed decision about whether or not to continue your child's participation. You have been given the opportunity to ask questions about the research, and you have received answers concerning areas you did not understand.

Upon signing this form you will receive a copy

I willingly consent to allow my child to participate in this research

Parent/ Guardian Signature

Printed Name

Date

Time

The parent/guardian has had the opportunity to have questions addressed. The parent/guardian willingly agrees to allow his/her child to be in the study.

Signature of investigator or

Printed Name

Date

Time

Co-Investigator 
Table C2. Assent Form

ASSENT FORM

Principal Investigator: Sandrey, Michelle

Department: $\quad$ College of Physical Activity and Sport Sciences

\section{Study Title:}

Does Hydration Affect Performance and Win Percentages of High School Wrestlers?

\section{Co-Investigator(s):}

Brausch, Joseph

\section{Contact Persons}

In the event you experience any side effects of injury related to this research, you should contact Joseph M. Brausch, ATC at (513) 659-3935 or at JBrausch@mix.wvu.edu. If you have any questions, concerns, or complaints about this research you can contact Dr. Michelle A. Sandrey, PhD, ATC at (304) 293-0870 or at msandrey@mail.wvu.edu. For information regarding my rights as a research subject, I may contact the Executive Secretary of the Review board at (304) 293-7073.

\section{Introduction}

You, , have been asked to participate in this research study, which has been explained to you by Joseph M. Brausch, ATC. This study is being conducted by principal investigator Michelle Sandrey, $\mathrm{PhD}, \mathrm{ATC}$ and the co-investigator Joseph M. Brausch, ATC. This research is being conducted to fulfill the requirements for a master's thesis in athletic training in the College of Physical Activity and Sport Sciences at West Virginia University, under the supervision of Dr. Michelle A. Sandrey PhD, ATC.

\section{Purpose of the Study}

The purposes of the study are to determine if 1) there is a difference between varying hydration levels over 24 hours from baseline, 2) do those who have the lowest average specific gravity perform better by having a higher win percentage and, 3) do those with higher average levels of hydration perform better by earning more team points in matches. WVU expects to enroll approximately 20 subjects in this study.

\section{$\underline{\text { Description of Procedures }}$}

The study will be conducted at Albert Gallatin High School, 1119 Township Dr Uniontown, PA 15401. All testing procedures will be performed in the Albert Gallatin Wrestling team's locker room and coaches office at Albert Gallatin High School. There is also a private restroom in the coach's office where samples will be given. You will be asked to perform a hydration test much like the state mandated test required at the beginning of the season. The major difference will be 
that no body fat analysis will be conducted. You will be placed into one of two groups based on your competition history throughout the season. The intervention group will be decided by those wrestlers that compete in at least $75 \%$ of competitions. Those not included in the intervention group will be in a control group to compare results to. If you choose to participate you will be asked to provide a small urine sample and weigh in the day before a competition and then again the day of the competition. This will be done multiple times throughout the regular season. There are 12 competitions scheduled this year so they will be tested 24 times. Once 24 hours before a competition and again the day of the competition. These specific gravity measurements will show how hydrated you are and will place you into one of two groups, a high average specific gravity group and a low specific gravity group. These groups will be compared to each other in regards to win percentage and also in regards to team points. We will investigate to see if hydration, measured by specific gravity, has an effect on win percentage and team points earned per match and thus on your performance.

If you choose to participate, you will be contacted by the co-investigator on various occasions to perform the testing procedures. These dates are subject to change due to changes in the regular wrestling schedule. I understand that there specific testing procedures to be followed. I understand that the only person to know my results and to record my results will be Joseph M. Brausch, BS, ATC and that I will be referred to as a number during the course of the study to protect my personal and private information.

\section{$\underline{\text { Risks and Discomforts }}$}

You understand that you may experience some mental discomfort or anxiety; however you nor anyone other than the researcher will not know their specific gravity during the testing. I understand that there are minimal risks while performing the hydration test. The co-investigator will maintain a safe, private environment during the hydration test. I am aware that a male recorder will be present for all males performing the test and a female will be present for any females performing the hydration test. I understand that every precaution has been taken to prevent you from being injured during the hydration test. Should any injury occur, I understand that Joseph M. Brausch, ATC will provide first aid and will make any necessary referrals.

\section{Alternatives}

You do not have to participate in this study. The normal alternative is to participate in wrestling practices and competitions without the hydration tests throughout the season.

\section{$\underline{\text { Benefits }}$}

You may receive benefits from this study if they participate. Benefits include knowledge gained from the study on how hydration may affect their performance. Additionally the knowledge gained from this study my benefit other wrestlers. 


\section{Financial Considerations}

If you are injured while participating in this study you will be responsible for the cost of care provided. You understand that you will not receive any monetary compensation for participation in this study.

\section{Confidentially}

Subjects Name:

ID Number:

We know that information about you and your health is private. We are dedicated to protecting the privacy of that information. Because of this promise, we must get your written authorization (permission) before we may use or disclose your protected health information or share it with others for research purposes. The form gives that permission. It also helps us make sure that you are correctly told how this information will be used or disclosed. Please read the information below carefully before signing this form. Please ask any questions you may have about this form or its uses. You can decide to sign or not to sign this authorization form. However, if you choose not to sign the authorization form, you will not be able to take part in the research study. Whatever choice you make about this research study, it will not have an effect on your access to medical care.

\section{USE AND DISCLOSURE COVERED BY THIS AUTHORIZATION. DO NOT SIGN A} BLANK FORM. You or your authorized representative should thoroughly read the information below before signing this form. This form will authorize the following person(s), class(es) of persons, and/or organization(s) to disclose, use, and receive the information: WVU, Michelle A. Sandrey, PhD., ATC, Joseph M. Brausch, ATC. The research site(s) carrying out this study includes WVU and Albert Gallatin High School. It also includes each site's research staff and medical staff. Health care providers who provide services to you as part of this research study include Joseph M. Brausch, ATC. If, during the course of the research, the institution listed above merges with, or is purchased by, another company or institution, this authorization to use or disclose protected health information in the research will extend to the Successor Company or institution.

SPECIFIC UNDERSTANDINGS: By signing this research authorization form, you give permission for the use and/or disclosure of your protected health information described above. The purpose for the uses and disclosures you are authorizing us to carry out the research study explained to you during the informed consent process. It is also to ensure that the information relating to the research is available to all parties who may need it for research purposes. Your protected health information may be used as necessary for your research-related treatment. This information may be re-disclosed or used for other purposes if a recipient described in this form is not required by law to protect the privacy of the information. You have a right to refuse to sign this authorization. Your health care outside the study, the payment for your health care, and your health care benefits will NOT be affected if you do not sign this form. However you will NOT be able to take part in the research study described in this authorization if you do not sign this form. If you sign this authorization, you will have the right to cancel it at anytime, except to the extent that WVU has already taken action based upon your authorization or needs 
the information to complete analysis and reports of data for this research study. To cancel this authorization, please write to the Principal Investigator, Michelle A. Sandrey, Ph.D, at: West Virginia University, PO box 6116, Morgantown, WV 26505. You will NOT be allowed to see or copy the information described on this form as long as the research is in progress, but you have a right to see and copy the information upon completion of the research in accordance with hospital policies. You have a right to receive a copy of this form after you have signed it. Expiration Date: NONE

In any publications that result from this research, neither your name nor any information from which you might be identified will be published without your consent.

THE SUBJECT OR HIS/HER AUTHORIZED REPRESENTATIVE MUST BE PROVIDED WITH A COPY OF THIS FORM AFTER IT HAS BEEN SIGNED.

SIGNATURE:

I have read this form and all of my questions about this form have been answered. By signing below, I acknowledge that I have read and accept all of the above

Signature of subject or

Authorized Representative: Date:

Printed Name of Subject or Authorized Representative: Date:

Print Name of Individual Explaining this Research Authorization form

Address:

Telephone: (Daytime)

(Evening)

E-mail Address (optional):

\section{Voluntary Participation}

Your participation in this study is voluntary. You are free to withdraw your consent for yourself to participate in this study at any time. Refusal to participate or withdrawal will not affect your future care, class standing, or grades and will involve no penalty to you. In the event that new information becomes available that may affect your willingness for you to participate in this study, this information will be given to you so that you can make an informed decision about 
whether or not to continue your participation. You have been given the opportunity to ask questions about the research, and you have received answers concerning areas you did not understand.

Upon signing this form you will receive a copy

I willingly agree to be in this research

Signature of Subject

Printed Name

Date

Time

The child has had the opportunity to have questions addressed. The child willingly agrees to allow his/her child to be in the study.

Signature of investigator or

Printed Name

Date

Time 
Table C3. Demographic Questionnaire

1. Age:

2. Year in school circle one: FR SO JR SR

3. Wrestling weight class, circle one:

$\begin{array}{llllllllllllll}103 & 112 & 119 & 125 & 130 & 135 & 140 & 145 & 152 & 160 & 171 & 189 & 215 & 285\end{array}$

4. Total number of years wrestling (including the 2010-2011 season)

5. How much weight do you drop during a week ( on average): lbs 
Table C4. Minimum Wrestling Weight Certification Testing Form

\section{WRESTLING MINIMUM WEIGHT CERTIFICATION INDIVIDUAL PROFILE FORM}

Name:

Last, $\quad$ First

Grade:

School:

Gender: M / F Age:

Birth date:

X X X X X X X X X X X X X X X X X X X X X X X X X X X X X X X X X X X X X X X X DATA COLLECTION

Urinalysis: Specific gravity of urine:

\section{Indicate pass or fail}

Assessor:

Must be 1.025 or lower for testing to continue

Alpha Weight:

lbs.

Skin fold Measurements ( Take three measurements in each location)

Triceps:

Subscapular:

Abdominal:

Assessor Name:

Date: 
Table C5. Dates for Data Collection

$\underline{\text { First Testing Dates ( } 24 \text { hours Pre-Competition) }}$

Home Competitions

- December 14, 2010

- December 15, 2010

- January 4, 2011

- January 18, 2011

Away Competitions

- December 9, 2010

- December 21, 2010

- December 28, 2010

- January 6, 2011

- January 11, 2011

- January 13, 2011

- January 25, 2011

- January 28, 2011

- February 4, 2011

$\underline{\text { Second Testing Dates (Pre-competition) }}$

Home Competitions

- December 15, 2010

- December 16, 2010

- January 5, 2011

- January 19, 2011

$\underline{\text { Away Competitions }}$

- December 10, 2010

- December 22, 2010

- December 29, 2010

- January 7, 2011

- January 12, 2011

- January 14, 2011

- January 26, 2011

- January 29, 2011

- February 5, 2011 
Table C6. Recording Sheet

Date:

Subject Number

Specific Gravity

Weight

1

2

3

4

5

6

7

8

9

10

11

12

13

14

15

16

17

18

19

20 
1. Wrestlers will be asked to provide a small urine sample into a sample cup in a private bathroom.

2. The recorder will take a drop of urine from the sample cup and place it on the refractometer for reading.

3. The specific gravity reading will be recorded on the data sheet.

4. The excess urine will be disposed of in the toilet and the sample cup placed in a biohazard bag

5. The refractometer will be cleaned using distilled water and soft rags.

6. The athlete will then be asked to step onto the exact middle of the scale and asked to stand still.

7. The weight will be recorded from the digital scale to the tenth of a pound on the data collection sheet.

8. All wrestlers will be identified by a code.

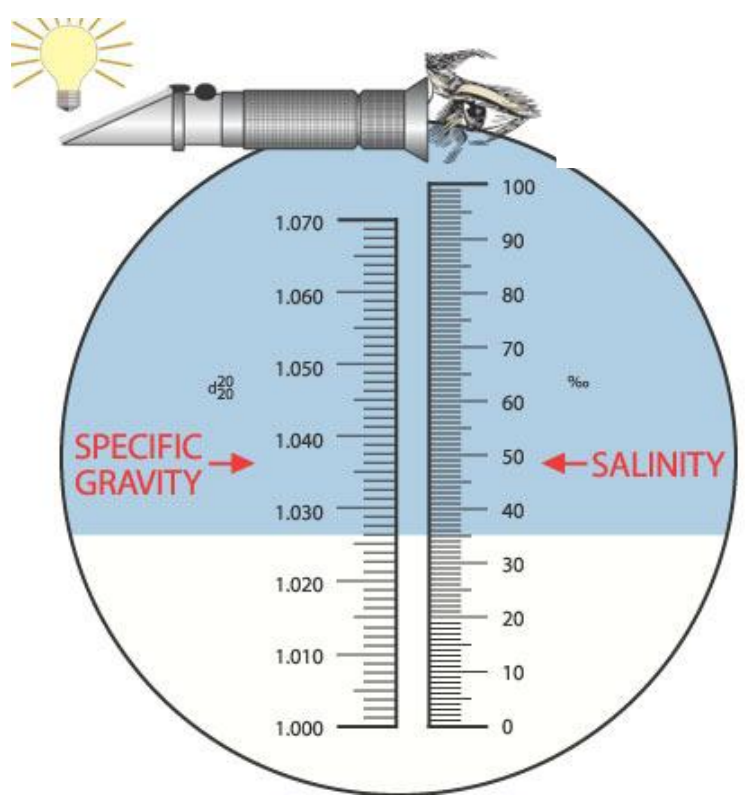


Table C8. Team Points Awarded

Pin $1^{\text {st }}$ period- +/- 8pts

Pin $2^{\text {nd }}$ period- $+/-7$ pts

Pin $3^{\text {rd }}$ period- $+/-6$ pts

Technical fall- +/- 5pts

Major decision- +/- 4pts

Decision- +/- 3 pts. 
Table C9. Letter to Parents/Guardians and Students

Dear Parents/Guardians and Student,

First let me introduce myself. My name is Joe Brausch, ATC. I am a Graduate Student Athletic Trainer from West Virginia University completing a Masters Degree in Athletic Training. As part of my degree work I am required to perform research to graduate. I have chosen to focus my research on wrestling and hydration because wrestlers are notorious for competing and practicing at unsafe levels of dehydration.

This study will be conducted in the privacy of the wrestling locker room. I will follow the same procedures of the state required hydration and weight certification test your child is required to perform each wrestling season. The only one to know results of the hydration testing will be myself. The hydration testing will have no effect on their competition, their minimum wrestling weight, or be a factor into any matches. No data will be posted on-line and your child will be identified by a number so that in the event there is a breach of security the only one that will have knowledge of which number pertains to that individual will be myself. It is important to me that your child's personal information stays safe.

Each year your child is required to take a hydration test at the beginning of each season. The test is designed to limit the amount of weight your child can drop each year. It prevents them from dropping to an unsafe body fat percentage. The test includes a hydration assessment performed by giving a small urine sample. A drop is placed on an instrument called a refractometer which measures specific gravity and determines how hydrated they are. If they pass this part of the test their body fat is measured by using a skin fold measurement and a set of calipers. After that their body weight is measured, these numbers are then put into a computer program which determines their overall body fat percentage, how much weight they can drop over the season safely, and what their minimum wrestling weight should be.

In my research I will be performing essentially the same test multiple times. If you and your child choose to participate your child will be asked to provide a small urine sample and weigh in the day before a competition and then again the day of the competition. This will be done multiple times throughout the regular season. There are 12 competitions scheduled this year so they will be tested 24 times. Once 24 hours before a competition and again the day of the competition. For home competitions the wrestler will perform the test 2 hours before the start of the matches and for away competitions the wrestler will perform the hydration test before the bus leaves for the competition. I hope to show that there is a relationship between dehydration and performance. If you have any questions at any time about the study or are concerned with anything feel free to call me or email me.

Thank you in advance for your participation,

Joe Brausch, ATC

(513) 659-3935

JBrausch@mix.wvu.edu

West Virginia University Institutional Review Board acknowledgement of this study is on file 
Figure C1. Flow Chart of First Design Testing Procedures

Purpose \#1: Is there a relationship between varying hydration levels and performance

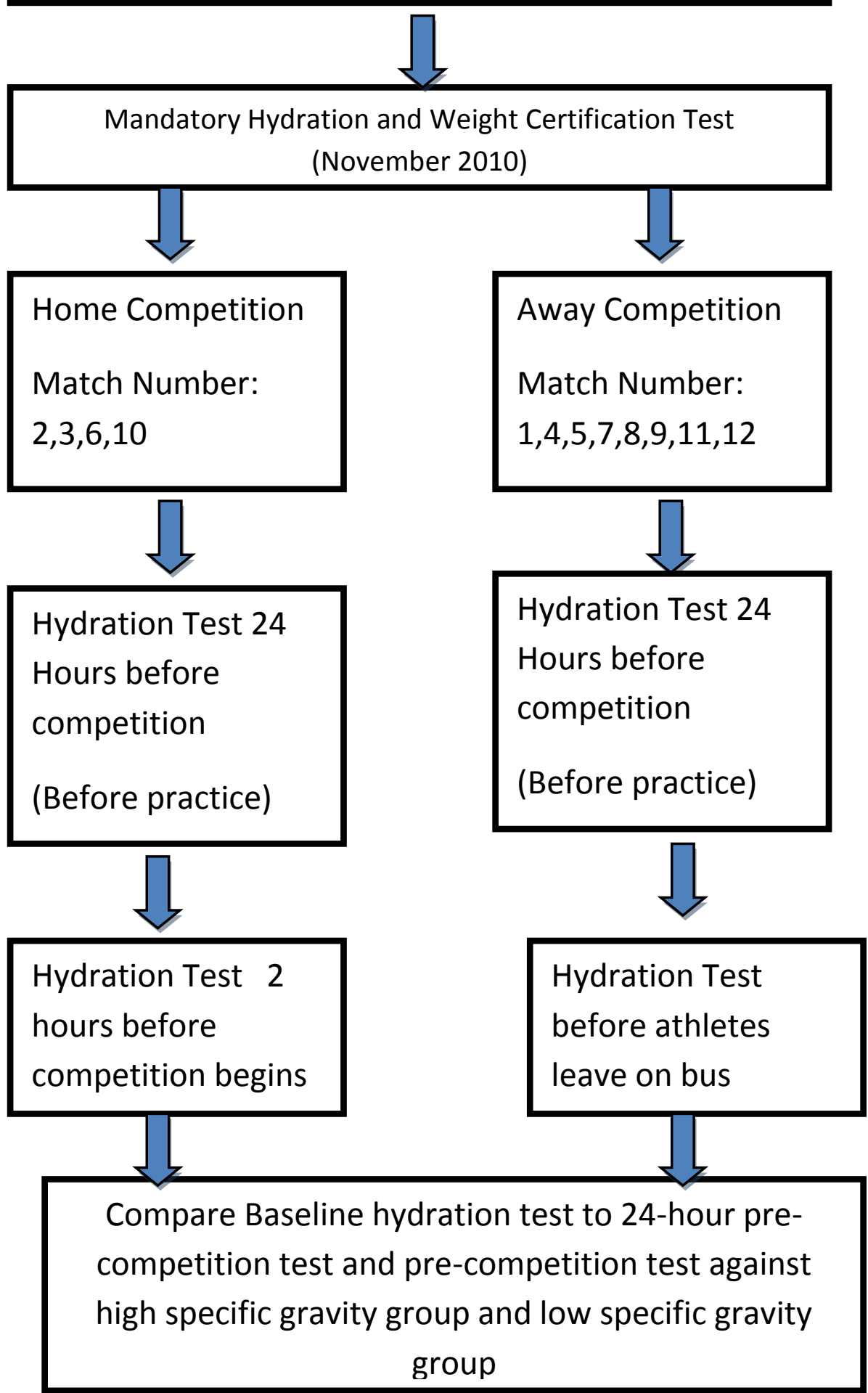




\section{Purpose \#2: Do those with the smallest} average specific gravity have a better win percentage

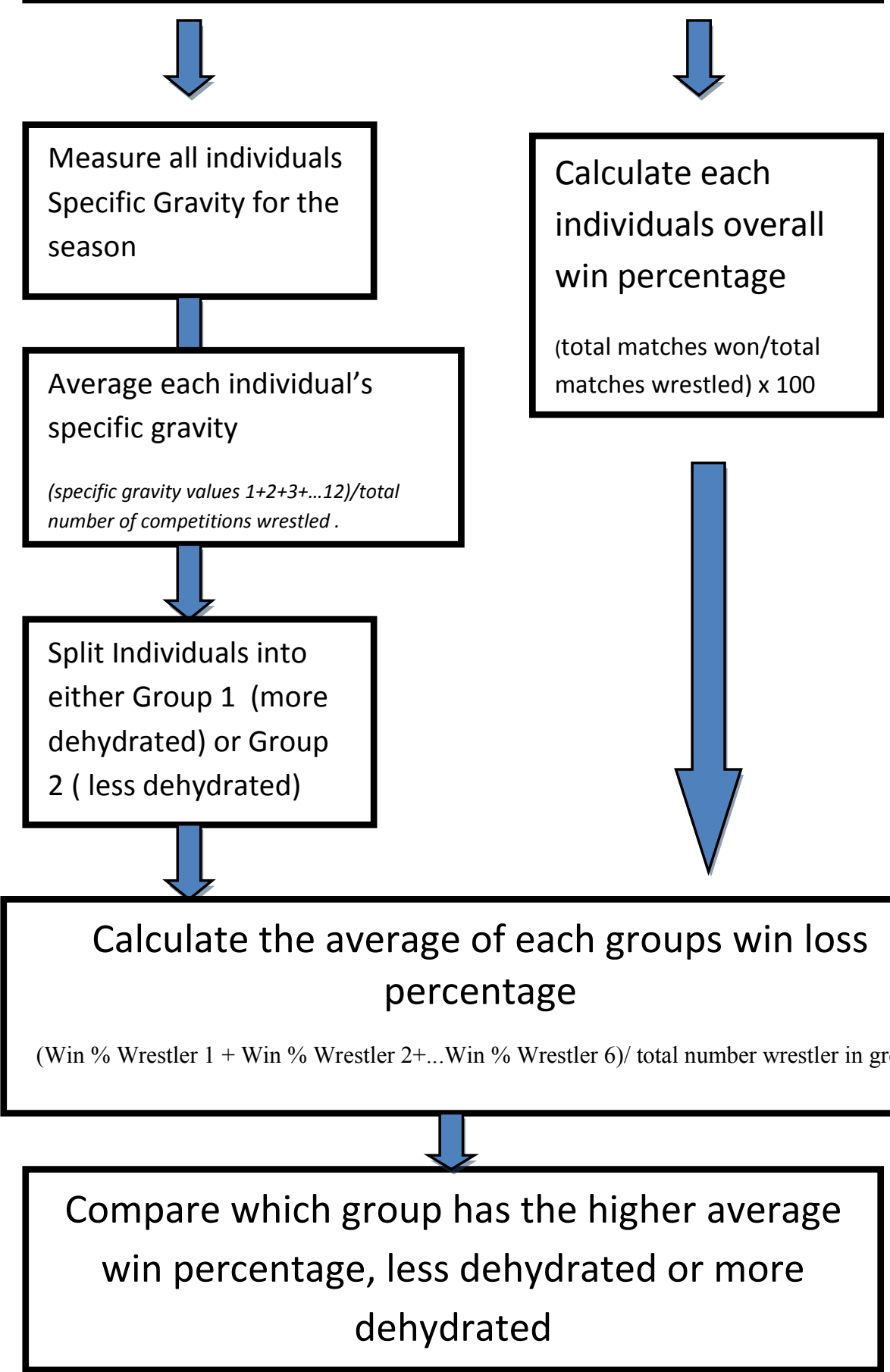


Figure C3. Flow Chart of Third Purpose Testing Procedures

\section{Purpose \#3: Do athletes with a higher average hydration status earn more team points during the matches}

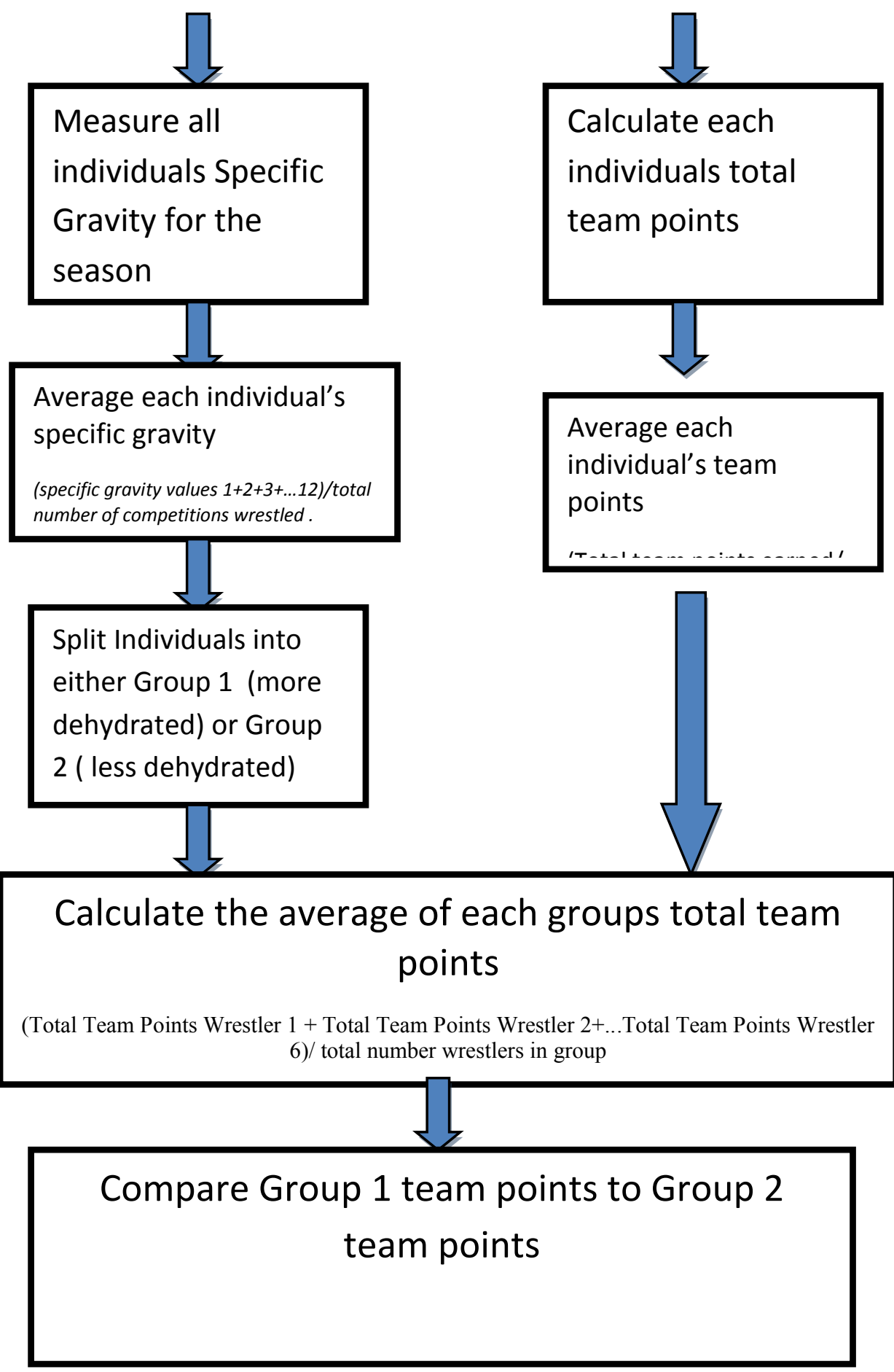


APPENDIX D

ADDITIONAL RESULTS

Table D1. Descriptive Data

Subject Age Year in school WT Class \# Yrs Wrestled Avg. wt loss/week

\begin{tabular}{llllll}
1. & 15 & 1 & 130 & 6 & 4 \\
2. & 15 & 1 & 140 & 5 & 5 \\
3. & 17 & 3 & 119 & 3 & 6 \\
4. & 14 & 1 & 125 & 4 & 6 \\
5. & 16 & 2 & 140 & 2 & 5 \\
6. & 18 & 4 & 160 & 7 & 7 \\
7. & 15 & 1 & 130 & 3 & 4 \\
8. & 18 & 4 & 135 & 6 & 11 \\
9. & 18 & 4 & 215 & 5 & 4 \\
10. & 17 & 4 & 152 & 10 & 7 \\
11. & 15 & 1 & 130 & 3 & 4 \\
12. & 18 & 4 & 285 & 2 & 0 \\
13. & 18 & 4 & 171 & 7 & 3 \\
14. & 17 & 4 & 125 & 9 & 3 \\
15. & 17 & 3 & 140 & 6 & 7 \\
\hline
\end{tabular}



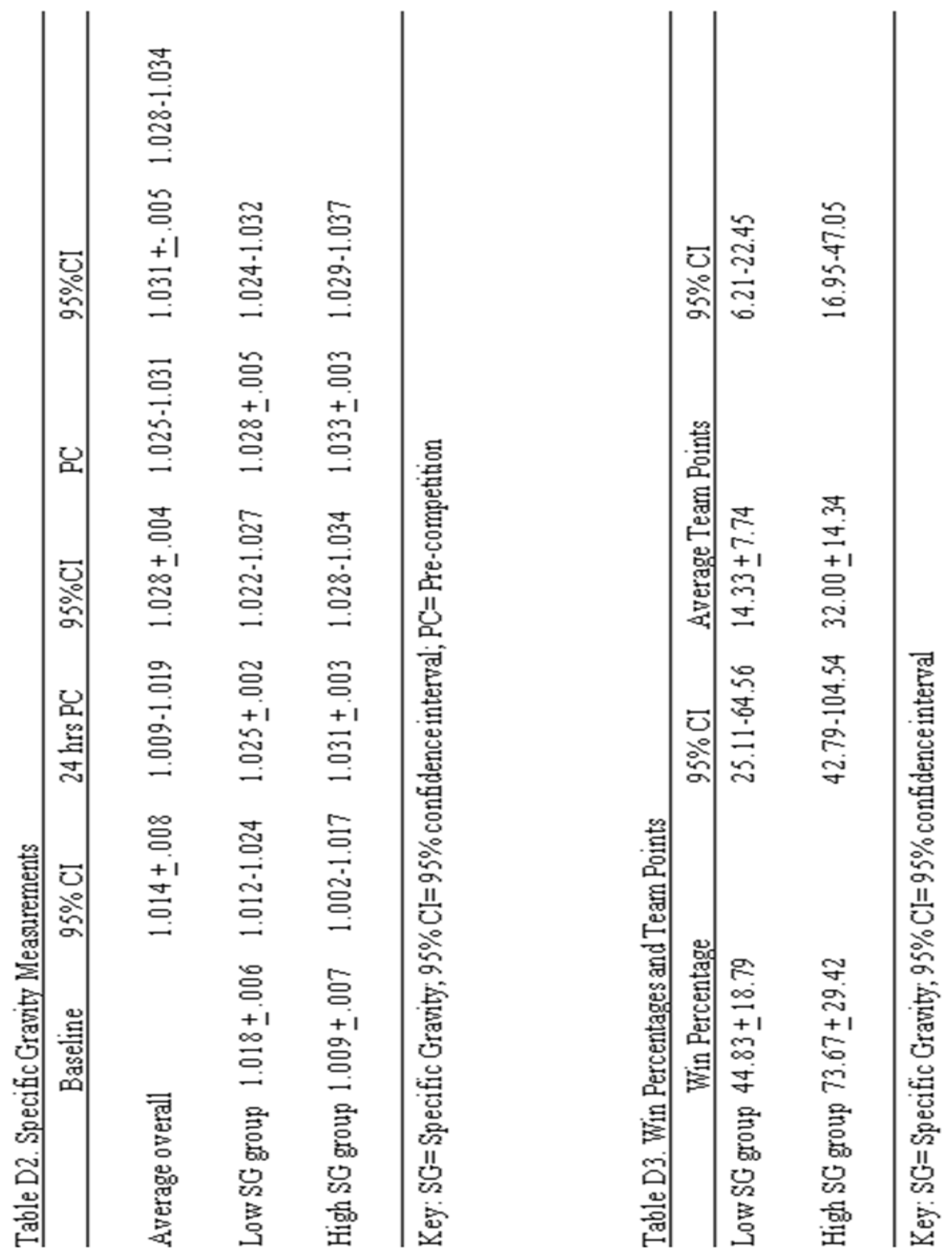
Figure D1. Specific Gravity Measurements Over Time

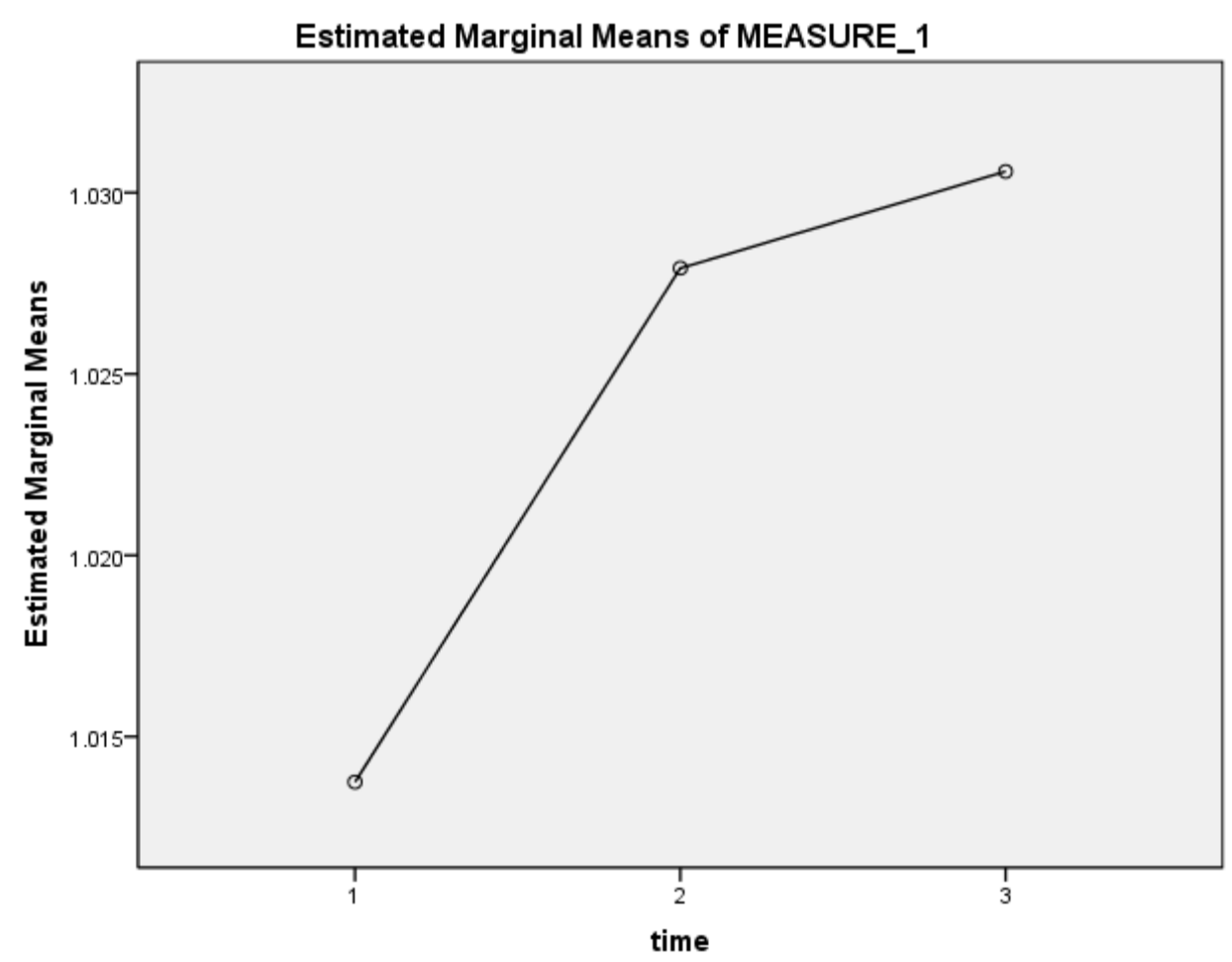

Figure D2. Specific Gravity Measurements for Group and Time

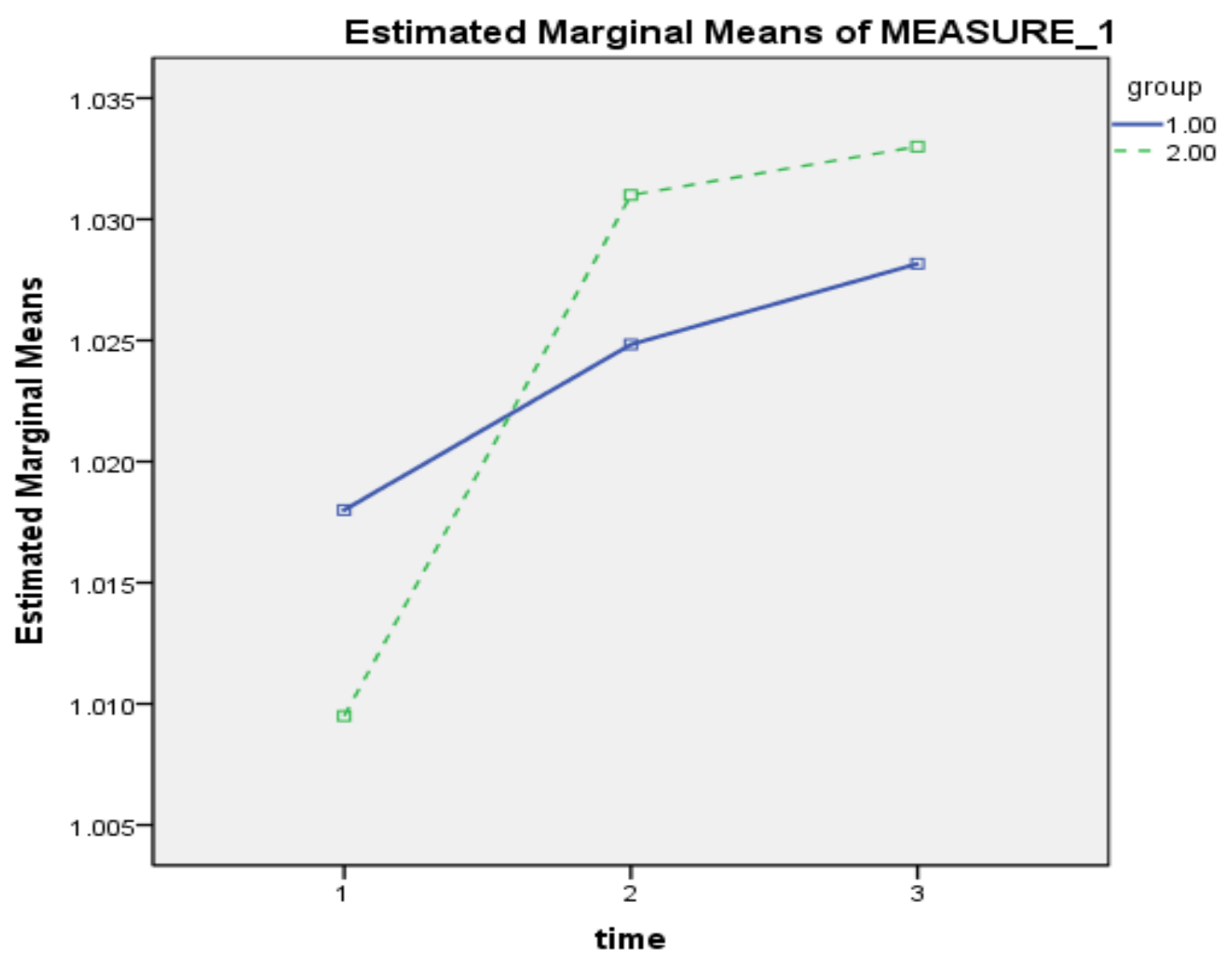


Figure D3. Average Specific Gravity and Percentage Weight Change

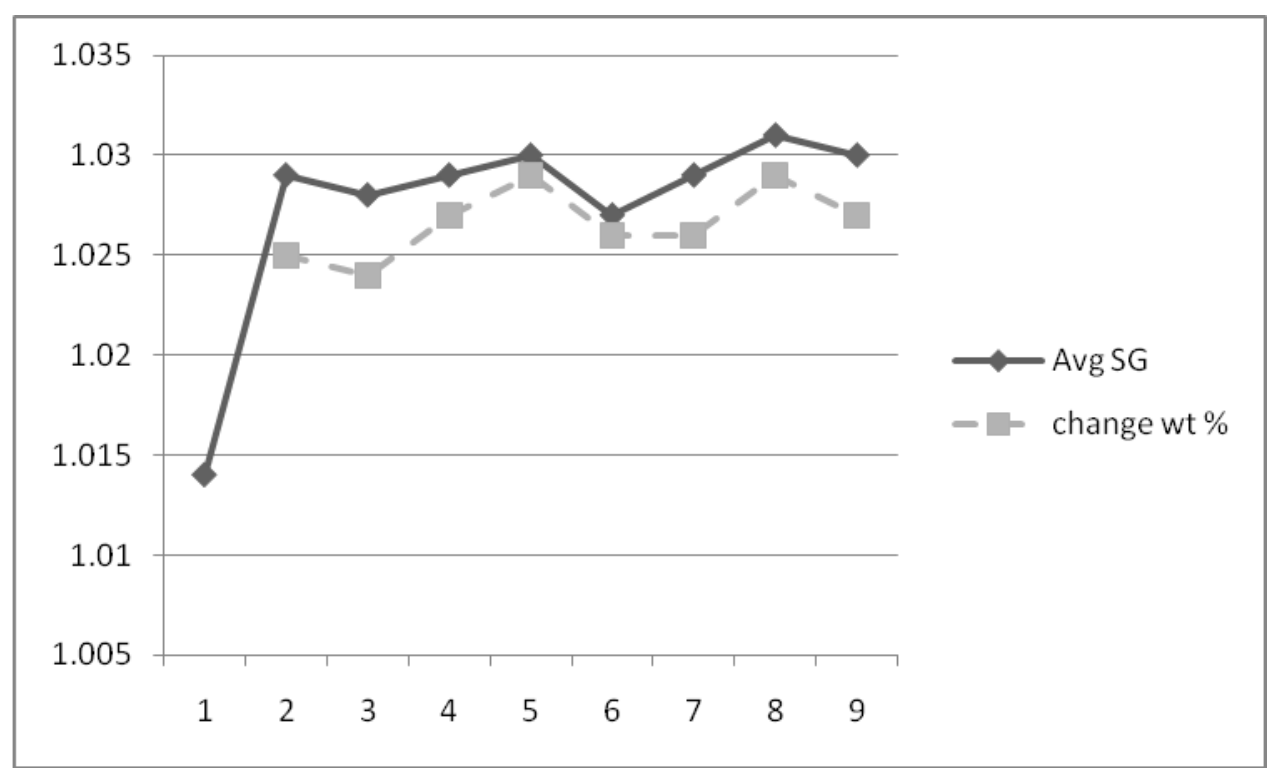

Key:

$\begin{array}{lrrrrrrrrr} & \text { Baseline } & \text { Match 1 } & \text { Match 2 } & \text { Match 3 } & \text { Match 4 } & \text { Match 5 } & \text { Match 6 } & \text { Match 7 } & \text { Match 8 } \\ \text { Avg SG } & 1.014 & 1.029 & 1.028 & 1.029 & 1.03 & 1.027 & 1.029 & 1.031 & 1.03 \\ \text { change wt \% } & 1.025 & 1.024 & 1.97 & 1.3 & 1.026 & 1.026 & 1.029 & 1.027\end{array}$




\section{APPENDIX E}

\section{RECOMMENDATION FOR FUTURE RESEARCH}

1. Increase the sample size of the subjects. When an ANOVA or ANCOVA is performed there should be a sample size of 20 or more subjects. This increases statistical power and would generalize the results better. Furthermore, effect size of results should be considered.

2. Subject's previous experience, skills, and psychological status should be taken into account. These factors can greatly influence win percentages and individual match outcomes as well as dehydration.

3. Subjects should be included from other schools. This may help to generalize the results and may help show a greater statistical significance.

4. Subjects should be examined on how weight loss was performed each week. Some subjects reported attempting to lose far more weight than allowed weekly by the National Wrestling Coaches Association calculator. It may show that certain practices dehydrate subjects more than others and could affect win percentages or team points.

5. Specific gravity should be measured both before and after practices and the day of the match. Some subjects may have been able to recover from high specific gravities the day of competition before the first match. 


\section{ADDITIONAL REFERENCES}

30. Volpe S, Poule K, Bland E. Estimation of prepractice hydration status of national collegiate athletic association division I athletes. J Athl Train. 2009;44(6):624-629.

31. McDermott B, Casa D, Yeargin S, Ganio M, Lopez R, Mooradian E. Hydration status, sweat rates, and rehydration education of youth football campers. J Sport Rehabil. 2009;18(4):535-552.

32. Powell J. Barber-Foss K. Sex-related injury patterns among selected high school sports. Am J Sports Med. 2000; 28:385-91

33. Center for Disease Control. Hyperthermia and dehydration related deaths associated with intentional rapid weight loss in three collegiate wrestlers- north Carolina, Wisconsin, and Michigan. J Am Med Assoc. 1997;279(11):824-825

34. National Collegiate Athletic Association. 2009 NCAA Wrestling rules and interpretations.

35. Remick D, Chancellor K, Pederson J, Zambraski E, Sawka M, Wenger C. Hyperthermia and dehydration-related deaths associated with intentional rapid weight loss in three collegiate wrestlers--North Carolina, Wisconsin, and Michigan, J Am Med Assoc. 1997.

36. Weinberg AD, Minaker KL, American medical association CoSA. Dehydration: evaluation and management in older adults. J Amer Med Assoc 1995;274:1552-6

37. Zetterström R. Voluntary and therapeutic causes of water intoxication and hypertonic dehydration: perinatal risks in mother and offspring. Scandinavian J Nutr. 2003;47(3):108-110

38. Nitzke, S.A., Voichick, S.J., Olson,D. Weight cycling practices and long-term health conditions in a sample of former wrestlers and other collegiate athletes. J Athl Train. 1992: 27(3): 257-261.

39. Sawka MN, Montain SJ. Fluid and electrolyte supplementation for exercise heat stress. Am J Clin Nutr. 2000;70(2)564-572

40. Houston M, Marrin D, Green H, Thomson J. The effect of rapid weight loss on physiological functions in wrestlers. Phys Sports Med. 1981;9(11):73-78

41. Armstrong LE, Casa DJ, Maresh CM, Ganio MS. Caffeine, fluid electrolyte balance, temperature regulation and exercise-heat tolerance. Exerc Sport Sci Rev 2007;35: 135140 
42. Costill, DL, Sparks KE. Rapid fluid replacement following thermal dehydration. J Appl. Physiol. 1976;34:299-303

43. Treasure D, Monson J. Relationship between self-efficacy, wrestling performance, and affect prior to competition. Sport Psyc. 1996;10(1):73-83

44. NFSHSA. NFHS approves new weigh-in rules. Ath Mgt. 17.5, Aug-Sept 2005, http://www.momentummedia.com/articles/am/am1705/wuweighin.htm

45. Patel A, Mihalik J, Notebaert A, Guskiewicz K, Prentice W. Neuropsychological performance, postural stability, and symptoms after dehydration. J Athl Train. 2007;42(1):66-75.

46. Roessingh AS, Drukker A, Guignard JP. Dipstick measurements of urine specific gravity are unreliable. Arch Dis Child. 2001;85:155-157

47. Manz F, Wentz A. 24-h hydration status: parameter, epidemiology and recommendations. Eur J Clin Nutr. 2003;57:10-18

48. Shirreffs SM. Markers of hydration status. Eur J Clin Nutr. 2003;57:6-9

\footnotetext{
John H. Virginia University Libraries,
ou=Acquisitions Department Hagen
} 